\title{
Illuminating the Surface Corona of Biogenic Silver Nanoparticles
}

\section{Sunil Rajput, Mark McDermott}

Submitted date: 05/05/2020 Posted date: 07/05/2020

Licence: CC BY-NC-ND 4.0

Citation information: Rajput, Sunil; McDermott, Mark (2020): Illuminating the Surface Corona of Biogenic Silver Nanoparticles. ChemRxiv. Preprint. https://doi.org/10.26434/chemrxiv.12249836.v1

Biogenic nanoparticles are attractive due to their unique surface chemistry compared to chemical counterparts. Underpinning the importance of the surface layer or corona is the interaction between the nanoparticles and the environment. The surface corona provides biological identity, physical structure, colloidal stability and a chemical scaffold for modification. Understanding the structure and composition of the corona that surrounds nanoparticles enables rational design for applications. Previous investigations examining biogenic nanoparticles have purported a coating comprised of biomolecules, however a defined structure is extremely limited. We address this limitation through a detailed examination involving both in situ analyses of silver nanoparticle dispersions (indirect) produced by Fusarium oxysporum and desorbing the surface corona (direct). Using a series of orthogonal characterization techniques we show evidence the surface corona of biogenic silver nanoparticles is comprised of a thin mixed layer of peptides and carbohydrates. We propose the origin of these peptides is from adaptive or protective proteins triggered by environmental stress. The differences and limitations in our two approaches are highlighted. Our findings make it clear that methods used to characterize the inherent surface corona of biogenic silver nanoparticles should be carefully documented for consistent and judicious interpretations.

\section{File list (2)}

Illuminating the surface corona of biogenic silver nanoparti... (2.68 MiB) view on ChemRxiv • download file Illuminating the surface corona of biogenic silver nanoparti... (1.62 MiB) view on ChemRxiv • download file 


\title{
Illuminating the surface corona of biogenic silver
}

\section{nanoparticles}

\author{
Sunil Rajput, ${ }^{\mathrm{a}, \mathrm{b}}$ and Mark T. McDermott ${ }^{\mathrm{a}}$ \\ ${ }^{a}$ University of Alberta, Department of Chemistry, Edmonton, Alberta, Canada T6G 2G2 \\ ${ }^{\mathrm{b}}$ InnoTech Alberta, Ecosystems and Plant Sciences, PO Bag 4000, Vegreville, Alberta, Canada \\ T9C $1 \mathrm{~T} 4$ \\ ${ }^{\dagger}$ Corresponding author
}

Contact information:

Dr. Mark T. McDermott

Department of Chemistry

11227 Saskatchewan Drive

University of Alberta T6G 2G2

Canada

780-492-3687

mmcdermo@ualberta.ca

Keywords: biogenic, silver nanoparticles, corona 


\section{Abstract}

Biogenic nanoparticles are attractive due to their unique surface chemistry compared to chemical counterparts. Underpinning the importance of the surface layer or corona is the interaction between the nanoparticles and the environment. The surface corona provides biological identity, physical structure, colloidal stability and a chemical scaffold for modification. Understanding the structure and composition of the corona that surrounds nanoparticles enables rational design for applications. Previous investigations examining biogenic nanoparticles have purported a coating comprised of biomolecules, however a defined structure is extremely limited. We address this limitation through a detailed examination involving both in situ analyses of silver nanoparticle dispersions (indirect) produced by Fusarium oxysporum and desorbing the surface corona (direct). Using a series of orthogonal characterization techniques we show evidence the surface corona of biogenic silver nanoparticles is comprised of a thin mixed layer of peptides and carbohydrates. We propose the origin of these peptides is from adaptive or protective proteins triggered by environmental stress. The differences and limitations in our two approaches are highlighted. Our findings make it clear that methods used to characterize the inherent surface corona of biogenic silver nanoparticles should be carefully documented for consistent and judicious interpretations. 


\section{Introduction}

Noble metal nanoparticles are of significant interest due their potential high value applications in medicine, electronics, agriculture, and energy. ${ }^{1-3}$ Widespread interest is principally driven by the optical properties and the high surface to volume ratio of metallic nanoparticles. In addition, the ability to synthesize metallic nanoparticles with controlled size and shape via scalable chemical methods enables researchers to obtain adequate quantities of such materials for a wide range of experiments. Though methods to chemically synthesize metallic nanoparticles are well established, there is increasing attention to biological organisms for nanoparticle synthesis. Such nanoparticles are typically produced in aqueous media with appropriate metal salts. Generally, this approach is considered to have lower environmental consequences and the resulting nanoparticles may possess chemical and physical properties that can be exploited in new or improved ways. A unique difference between biologically synthesized (biogenic) nanoparticles and chemically synthesized nanoparticles is the surface chemistry. Chemically synthesized nanoparticles are typically capped with citrate ions or a surfactant species that affords colloidal stability. Whereas, the surface chemistry of biogenic nanoparticles is complex with biomolecules affording enhanced colloidal stability ${ }^{4}$ and can be exploited for specialized applications. $\frac{5}{}$

The surface layer or corona of nanoparticles is known to define the biological identity of nanoparticles. ${ }^{6-10}$ Consequently, the impact of the surface layer with the surrounding environment can be beneficial or detrimental. ${ }^{11-13}$ The surface layer is considered to be loosely organized into two components, referred to as the "hard" and 
"soft" coronas with typically "long" and "short" adsorption/desorption cycles, respectively. ${ }^{9}$

${ }^{14}$ As Vroman first described using blood serum proteins, biomolecules in high abundance and lower molecular weight bind first to surfaces (e.g., albumin), which are later displaced by larger molecular weight biomolecules with higher affinity (e.g., fibrinogen). ${ }^{15-16}$ Understanding the chemical and physical makeup of the surface corona enables researchers to predict interactions within an environmental matrix. ${ }^{17-19}$ A biomolecule corona can be adsorbed to chemically synthesized nanoparticles by exposure to a variety of protein matrices. For example cationic gold nanoparticles have been exposed to blood serum forming a corona that influences recognition..$^{18}$

Our focus is on the inherent surface corona of biogenic nanoparticles. Detailed examination of the surface corona surrounding biogenic silver nanoparticles is valuable towards application development and understanding in vivo interactions. Within this context, researchers have surmised that the surface layer of biogenic nanoparticles consists of proteins. $\frac{20-23}{}$ Though several techniques have been used to probe the surface layer, the current body of evidence is inconclusive in providing structural and compositional details. Many of these previous reports principally provide indirect evidence of proteins using methods such as UV-visible spectroscopy, $\frac{24-25}{}$ vibrational spectroscopy, $\frac{21-22}{2}$ TEM-elemental spectroscopy imaging, ${ }^{26}$ SDS-PAGE analysis, $\frac{27-28}{}$ and electron microscopy ${ }^{29}$ investigating in situ silver nanoparticle (AgNP) dispersions post synthesis. Currently, there are no reports describing the surface layer of biogenic AgNPs (B-AgNPs) providing both direct and indirect structural and compositional evidence. 
This study characterizes the surface corona of silver nanoparticles produced by Fusarium oxysporum. Our approache involves both in situ analyses of silver nanoparticle dispersions (indirect) and desorption and analysis of the surface corona (direct). We present our results for the surface corona thickness, biomolecule composition, and relative chemical abundance. We highlight the differences between our approaches and discuss the implications of each. We also highlight our contrasting results of the surface layer and discuss implications from an ecological perspective.

\section{Experimental}

$\underline{\text { Reagents and materials }}$

Silver nitrate (ACS reagent grade, $\geq 99 \%$, lot\# MKBD7719 V, Sigma-Aldrich). 4nitrobenzene thiol (NBT, 80\%, lot\# MKBR2625, Sigma-Aldrich). Acetonitrile (HPLC grade, Caledon Laboratories and Fisher Scientific). Ethyl alcohol (anhydrous, Commercial Alcohols). BD Bacto yeast extract (product\# 212750, lot\# 5180630, Fisher), BD Bacto peptone (product\# 211677, lot\# 2306004, Fisher), dextrose (ACS reagent, product\# 73409, lot\# 720331, Fisher). Citrate-capped silver nanoparticle dispersion was purchased from Nanocomposix (lot\# DAG1159, San Diego, California). Citrate-capped vendor specifications: nanoparticle concentration of $0.02 \mathrm{mg} / \mathrm{L} ; 21 \pm 3 \mathrm{~nm}$ diameter based on TEM measurements, and $4 \times 10^{11}$ particles $/ \mathrm{mL}$. All reagents and materials were used as received unless otherwise specified. Deionized (DI) water with a resistivity of $18 \mathrm{M} \Omega \cdot \mathrm{cm}$ was used for all aqueous preparations unless otherwise noted. 


\section{Production and separation of biogenic silver nanoparticles}

A detailed description of silver nanoparticles production has been reported. ${ }^{4}$ The following is a brief description with changes to further optimize production. Fusarium oxysporum isolate 405 was initially cultured on potato dextrose agar (PDA) in the dark for seven days at $23^{\circ} \mathrm{C} \pm 2^{\circ} \mathrm{C}$. As an intermediate step prior to incubating in aqueous $1 \mathrm{mM}$ $\mathrm{AgNO}_{3}$ solution, F. oxysporum was set up as a liquid culture by removing one piece $(\sim 1 \mathrm{~cm} \mathrm{x}$ $2 \mathrm{~cm}$ ) of solid PDA growth medium containing mycelium and conidia and transferring to each sterile $500 \mathrm{~mL}$ Erlenmeyer flask containing $100 \mathrm{~mL}$ of sterile $1 \%$ yeast extract, $1 \% \mathrm{D}$ glucose and 1\% Bacto-peptone (1\% YGP). All inoculated flasks plus control medium flasks (i.e., no fungal inoculum) were incubated in the dark at $23^{\circ} \mathrm{C} \pm 2^{\circ} \mathrm{C}$ shaking at $150 \mathrm{rpm}$ for four days. Next, fungal biomass was separated from the culture broth by centrifuging at 2000 rpm for 5 min in swing out bucket centrifuge. Settled biomass was washed once with sterile DI water, centrifuged, and weighed after supernatant was decanted. Average fungal fresh (wet) weight and standard deviation was determined to be $42 \pm 4$ grams ( $\mathrm{n}=15)$.

Harvested washed fungal biomass was added to $100 \mathrm{~mL}$ of sterile $1 \mathrm{mM}$ aqueous $\mathrm{AgNO}_{3}$ solution (fresh) in sterile Nalgene PMP conical flasks with screw cap lids at $23^{\circ} \mathrm{C} \pm$ $2^{\circ} \mathrm{C}$. After inoculating, all flasks were incubated either at: a) $45^{\circ} \mathrm{C} \pm 0.3^{\circ} \mathrm{C}$, b) $50^{\circ} \mathrm{C} \pm 1^{\circ} \mathrm{C}$ or c) $75^{\circ} \mathrm{C} \pm 1^{\circ} \mathrm{C}$ under dark conditions with shaking at $100 \mathrm{rpm}$ for three days. Simultaneously, a negative control containing only silver nitrate solution and a positive control containing only fungus was maintained under identical experimental conditions. Fungal culture flasks were weighed post incubation. The average mass change and standard deviation in fungal culture was determined to be a loss of $0.2 \pm 0.01$ grams $(n=6)$. 


\section{Enrichment of biogenic nanoparticles}

Aqueous dispersions of AgNPs with fungi were sonicated for 20 min at $23^{\circ} \mathrm{C} \pm 2^{\circ} \mathrm{C}$ using a Branson 5510 ultrasonicator to separate nanoparticles from fungal mycelia post synthesis. After sonicating, aqueous dispersions with fungal mycelia were filtered using a sterile $0.1 \mu \mathrm{m}$ polyethersulfone membrane $250 \mathrm{~mL}$ vacuum filtration unit (Millipore, product\# SCVPU02RE, Massachusetts, USA). Negative control fungal cultures were treated the same as fungal cultures incubated with $\mathrm{AgNO}_{3}$. All samples were stored in the dark at $4^{\circ} \mathrm{C}$ until use.

\section{Extinction spectroscopy}

Biogenic nanoparticle dispersions were diluted by a factor of 2 and the citratecapped nanoparticle dispersion was diluted by a factor of 4 with deionized water before analysis for similar concentrations. Extinction spectra were collected in absorbance mode on a double-beam Perkin Elmer Lambda 35 spectrophotometer. Spectra were scanned from $900-300 \mathrm{~nm}$ with a scan rate of $960 \mathrm{~nm} / \mathrm{min}$. Deionized water was used as the blank. Measurements were done at room temperature. Both biogenic and citrate-capped nanoparticle dispersions were washed once with DI water prior to analyses.

\section{Dynamic light scattering (DLS)}

Hydrodynamic diameter of AgNPs was determined using a Malvern Zetasizer NanoZS. Results were collected with a $4 \mathrm{~mW}$ HeNe laser set at $633 \mathrm{~nm}$ with a $173^{\circ}$ back scattering angle and an avalanche photodiode detector. Measurements were performed under the following conditions: particle refractive index 1.590; particle absorption coefficient 0.028 for the Nanocomposix product and 0.118 for B-AgNPs (based on 
absorbance values recorded at $633 \mathrm{~nm}$ ); water refractive index 1.33 ; viscosity $0.8872 \mathrm{cP}$; and temperature $25^{\circ} \mathrm{C}$; equilibrated for 120 sec.; 15 runs; $\mathrm{n}=3$ measurements.

Hydrodynamic radii are calculated by the instrument software using the Stokes-Einstein equation for spherical particles. Hydrodynamic diameter $\left(D_{\text {hyd }}\right)$ reported represents the mean diameter based on intensity of scattered light.

\section{Zeta potential (ZP)}

Zeta potential of AgNPs was determined using a Malvern Zetasizer Nano-ZS. A 4 mW HeNe laser with $633 \mathrm{~nm}$ wavelength was used as the light source. All measurements were performed under the following conditions: temperature $25^{\circ} \mathrm{C}$; equilibrated for 120 sec.; 20 runs; $\mathrm{n}=3$ measurements; Smoluchowski model.

Transmission electron microscopy (TEM)

One mL of AgNPs were washed (1X) via centrifugation at 10,000 rpm for $10 \mathrm{~min}$ in an Eppendorf 5417R microfuge. The supernatant was carefully removed and the AgNP pellet was re-dispersed in $1 \mathrm{~mL}$ of DI water. A droplet of aqueous sample was deposited onto an ultra-thin carbon film coated copper 400 mesh grid (Electron Microscopy Sciences, product\# CF400-CU-UL). After one minute, excess suspension was wicked-off using Whatman filter paper and then the grid was air-dried at room temperature before analysis. For adlayer images, sample grids were examined under a 200 kV JEOL 2200 FS field emission TEM equipped with an in-column omega type energy filter. An objective aperture and an energy filter slit were applied to obtain zero-loss bright field (BF)-TEM images, which enhanced the contrast of thin organic layers around the AgNPs. Careful precautions

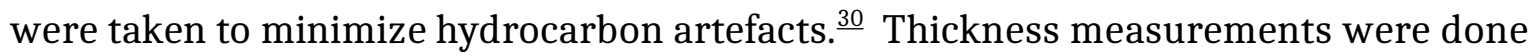


using the line profile tool (line width $=10$ ), which measures pixel intensity in Gatan Digital Micrograph (v2.31.734.0).

\section{$\underline{\text { SDS-PAGE }}$}

Proteins were separated using a $12 \%$ and 5\% discontinuous tris-glycine SDS-PAGE system (30\% acrylamide/bis solution; 29:1; 3.3\% crosslinker, Bio-Rad, catalog\# 161-

0156). $\frac{31}{}$ To remove proteins on the surface of biogenic AgNPs, samples were heated at $87^{\circ} \mathrm{C}$

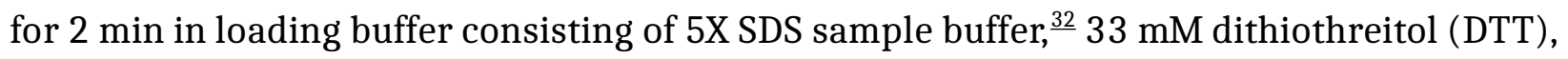
and $50 \%$ glycerol. Additional glycerol was added to the reduced sample buffer (buffer plus DTT) to increase viscosity of samples. This allowed for greater loading volume into the gel well. Control samples (i.e. fungus only and media) were treated the same. All samples were loaded (40 $\mathrm{\mu L} /$ well) into a $1.0 \mathrm{~mm}$ tris-glycine gel. For reference, Bio-Rad molecular weight standards (Precision Plus Protein Dual Xtra, catalog\# 161-0377) were run with samples (6 $\mu \mathrm{L} /$ well). Proteins were separated by electrophoresis in $1 \mathrm{X}$ tris-glycine-SDS Running Buffer at $50 \mathrm{~V}$ (initial $30 \mathrm{~min}$ ) for the stacking gel and then at $110 \mathrm{~V}$ for the resolving gel. After protein separation, gels were briefly rinsed with distilled water and put into a fixation solution ${ }^{33}$ consisting of $50 \%$ methanol, $10 \%$ glacial acetic acid, and $100 \mathrm{mM}$ ammonium acetate for $1 \mathrm{~h}$ with gentle agitation. After fixation, gels were again briefly rinsed with distilled water and stained with QC Colloidal Coomassie G-250 $\underline{34}$ stain (Bio-Rad, catalog\# 1610803) overnight ( 20 h) with gentle agitation. Note: short wash steps between fixation and staining are important for low molecular weight detection. Gels were destained with distilled water and imaged using ImageQuant RT ECL imager (v1.0.1, General Electric) in trans-illumination mode. 
In-gel digestion

Protein bands were excised from gel and digested with $10 \mathrm{ng} / \mu \mathrm{L}$ trypsin (Trypsin Gold, Mass Spectrometry Grade, Promega, catalog\# V5280) diluted with DI water and filtersterilized using a Millex GV $0.22 \mu \mathrm{m}$ syringe filter according to Shevchenko et al. $\frac{35}{5}$ Digested and extracted peptides were concentrated in $20 \mu \mathrm{L} 0.1 \%$ trifluoroacetic acid solution. Extracted peptides were desalted using $\mathrm{C} 18$ reversed-phase Zip-Tip pipette tips (Millipore, catalog\# ZTC18S008) following manufacturer's guidelines. Improved recovery was achieved by concentrating (Savant SpeedVac) the initial extraction volume by $\sim 4 \mathrm{X}$, repeated peptide binding/elution steps thrice, and dried final peptides extraction (Savant SpeedVac) to reconstitute in $0.1 \%$ formic acid for LC-MS/MS.

\section{MALDI-MS}

The matrix compound for peptide analysis was $\alpha$-cyano-4-hydroxycinnamic acid (HCCA) and sinapinic acid was used as matrix compound for proteins. Matrix solution was prepared in 50\% acetonitrile with a final concentration of $10 \mathrm{mg} / \mathrm{mL}$. C4 and C18 reversed-phase zip-tipped (Millipore) samples were mixed with the same volume of matrix solution and $0.8 \mu \mathrm{L}$ were spotted on an $800 \mu \mathrm{m}$ Bruker's anchorChip MALDI target (Bruker Daltonics) and air-dried. MALDI-MS was performed on an ultraflexXtreme ${ }^{\mathrm{TM}}$ MALDITOF/TOF (Bruker Daltonics) mass spectrometer in positive MS mode.

\section{$\underline{\mathrm{LC}-\mathrm{MS} / \mathrm{MS}}$}

Desalted peptides were subject to LC-MS/MS analysis on a UPLC (Waters Corporation) coupled with Q-TOF premier mass spectrometer (Waters Corporation). $5 \mu \mathrm{L}$ of the peptides were loaded onto a nanoAcquity UPLC system with peptide trap (180 $\mu \mathrm{m} \mathrm{x}$ 
$20 \mathrm{~mm}$, Symmetry C18 nanoAcquity ${ }^{\mathrm{TM}}$ column, Waters Corporation) and a nano-analytical column $\left(75 \mu \mathrm{m} \times 150 \mathrm{~mm}\right.$, Atlantis C18 nanoAcquity ${ }^{\mathrm{TM}}$ column, Waters Corporation). Desalting on the peptide trap was achieved by flushing trap with $1 \%$ acetonitrile, $0.1 \%$ formic acid in water at a flow rate of $10 \mu \mathrm{L} / \mathrm{min}$ for $5 \mathrm{~min}$. Peptides were separated with a gradient of $5-95 \%$ solvent B (acetonitrile, $0.1 \%$ formic acid) over $50 \mathrm{~min}$ at a flow rate of $350 \mathrm{~nL} / \mathrm{min}$. The column was connected to a Q-TOF premier (Waters Corporation) for ESI-MS/MS analysis.

\section{Protein identification}

MS/MS data were analyzed using Mascot (v2.3, Matrix science) $)^{\frac{36}{6}}$ and searching NCBI non-redundant (nr) protein database (20160529; 88,331,457 sequences; $32,419,248,901$ residues) and specifying Fungi taxonomy (5,570,423 sequences). Database search parameters were: parent ion and MS/MS tolerance were set to $0.1 \mathrm{Da}$ and $0.2 \mathrm{Da}$, respectively; no enzyme was specified and thus 0 missed cleavages were selected; oxidation on methionine, histidine, and tryptophan were selected as variable modification. Positive identification/extensive homology of protein/peptide were calculated using Mascot's scoring algorithm ${ }^{37}$ at $P<0.05$. Manual inspection of the original MS/MS spectra were often performed to ensure major $\mathrm{b}$ and y peaks in the MS/MS spectra were matched and explained. Ion score is calculated by $-10^{*} \log (P)$, where $P$ is the probability that the observed match is a random event $(P<0.05)$. Protein scores are derived from ions scores as a non-probabilistic basis for ranking protein hits.

\section{Nuclear Magnetic Resonance (NMR)}


${ }^{1} \mathrm{H}$ NMR spectra were collected on a $700 \mathrm{MHz}$ four channel Agilent VNMRS spectrometer, equipped with a Z-axis gradient HCN cold probe. Samples were dispersed in $\mathrm{H}_{2} \mathrm{O} / \mathrm{CH}_{3} \mathrm{CN} / 10 \% \mathrm{D}_{2} \mathrm{O}$ mixtures. Solvent suppression was performed using excitation sculpting; $\frac{38-39}{}$ suppressing both water and acetonitrile $\left(\mathrm{CH}_{3}\right)$ resonances. All data were referenced to 4,4-dimethyl-4-silapentane-1-sulfonic acid (DSS) added as $20 \mu \mathrm{L}$ of a $1 \% \mathrm{w} / \mathrm{v}$ solution in deionized water. ${ }^{40}$

\section{Results and discussion}

It is well established that the biological identity of a nanoparticle is typically defined by the surface corona or surface layer. ${ }^{\underline{8} 14}$ Detailed knowledge of the biological makeup of the corona on B-NPs will open pathways for unique applications, enable prediction possible biological interactions, and may provide mechanistic insights on NP synthesis. Detailed structural and compositional evidence is limited. Thus, we report our characterization of the end-products produced by Fusarium oxysporum. We indirectly examine the surface layer from in situ AgNP dispersions then turn our efforts to desorbing the layer for a direct examination by isolating the NPs from excess biomolecules in the dispersion. Our results are the first to thoroughly describe the composition and propose a model of the surface layer. The work described in this paper follows our previously published report ${ }^{4}$ demonstrating enhanced colloidal stability due to both steric and electrostatic effects. Herein, we present our results examining the surface layer and characterize AgNPs produced by F. oxysporum. 
Silver nanoparticles produced by Fusarium oxysporum at different culture temperatures were selected on the basis that protein secretion is inversely related to temperature over a finite period. ${ }^{4} \underline{23}$ Figure 1 contains a scheme of the workflow to investigate B-AgNPs from F. oxysporum. The initial set of characterization studies shown in Figure 1a involve in situ dispersions of nanoparticles. In situ dispersions consist of B-AgNPs dispersed in aqueous (DI) medium that were obtained after 20 min sonication and $0.1 \mu \mathrm{m}$ filtration of fungal biomass after three days incubation in $1 \mathrm{mM} \mathrm{AgNO}_{3}$ at a set temperature condition. Thus, B-AgNPs are coated with a surface layer comprised of biological macromolecules that are in dynamic equilibrium with free macromolecules in the medium. Our results of in situ dispersions is consistent with previous reports that use AgNPs recovered from fungal cultures. As we explain below, the results of our initial characterization studies (Figure 1a) led us to enrich B-AgNPs from excess biomolecules in the dispersion medium and use acetonitrile to desorb the surface layer for further analysis as shown in Figure 1b. Through this approach, we were able to enrich B-AgNPs and examine the desorbed surface layer using orthogonal techniques to reveal a "hard" corona composed of peptides consistent with stress response proteins and show evidence of carbohydrate detection. 


\section{Biogenic AgNPs}
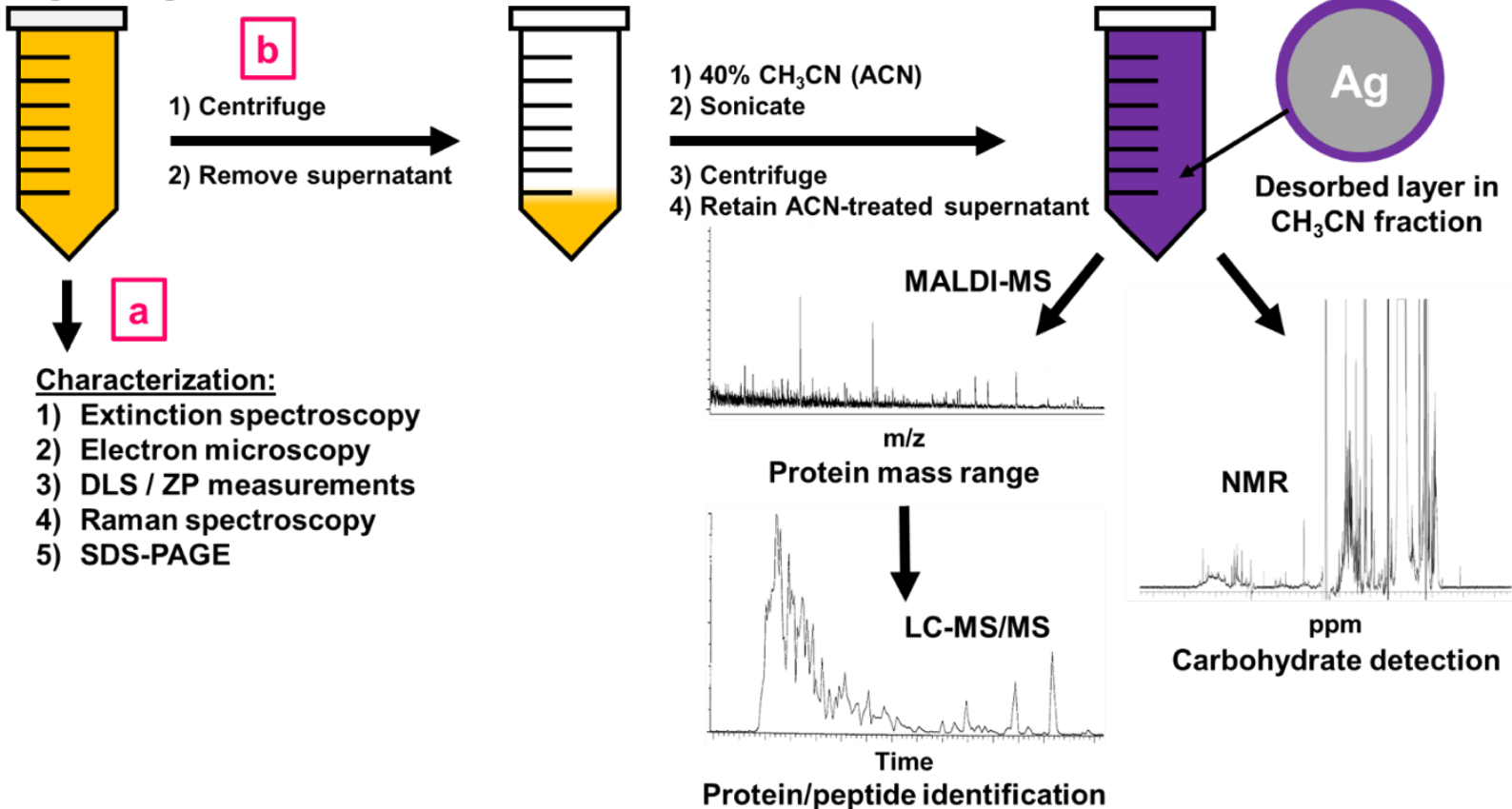

Figure 1. Characterization scheme for biogenic silver nanoparticles and the surface corona using indirect and direct methods. (a) In situ characterization of biogenic silver nanoparticles post filtration and separation from fungal biomass and indirect characterization of the surface corona. (b) Direct characterization of the surface corona by separation of excess biomolecules in the dispersion, desorption, and analyses of the biomolecules at the nanoparticle surface. 


\section{In situ surface characterization of silver nanoparticles}

\section{dispersion}

To measure the thickness of the layer, we characterized and compared a series of unmodified (i.e. native) biogenic, thiol modified (i.e., 4-nitrobenzene thiol; NBT) biogenic, and commercial citrate-capped AgNPs with a diameter of $\sim 20 \mathrm{~nm}$. The latter two AgNPs provide reference points of different molecular sizes for expected values of thiol and citrate layers. Differences observed in transmission electron micrographs should result from surface layer differences on AgNPs. Modified and unmodified AgNPs were imaged with high-resolution TEM to quantitatively measure the layer thickness. This technique has been previously used to image citrate,,$\underline{41}$ aliphatic thiols,,$^{42}$ and aryl diazonium ${ }^{43}$ derived films. Figure 2a-c show representative TEM images of individual AgNPs and the thickness of the surface film experiments. Figure 2a shows an unmodified AgNP produced by $F$. oxysporum. The layer thickness is measured to be $2.1 \pm 0.3 \mathrm{~nm}$. Visible variation in the layer thickness can be seen in Figure 2a. Asymmetry in the surface layer can be expected since the surface layer is suspected to be composed of biomolecules (e.g., proteins). We modified $20 \mathrm{~nm}$ AgNPs produced by F. oxysporum with NBT to displace the surface layer to calibrate our measurements as shown in Figure $2 \mathrm{~b}$. This approach allows us to calibrate our measurement to a known length of a NBT molecule. Also, as acid-base theory suggests, there is a greater propensity of -SH to form a strong interaction with Ag due to -SH soft nucleophilicity. As such, we can expect a symmetrical monolayer coverage as evidenced in Figure 2b. Similarly, Figure 2c shows a symmetrical film of citrate around chemically produced AgNPs, which is consistent with an expected length of citrate molecule. 
Fernández-Iglesias and Bettmer exposed citrate-stabilized gold nanoparticles to either bovine serum albumin or human serum and reported TEM results in their supplementary

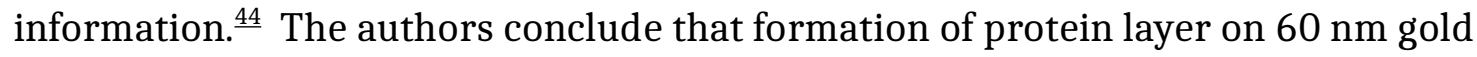
nanoparticles having a thickness of approximately $3 \mathrm{~nm}$ indicates monolayer coverage. Thicker regions $(7-8 \mathrm{~nm}$ ), as seen with $30 \mathrm{~nm}$ gold nanoparticles, indicates multilayer formation. Based on Fernández-Iglesias and Bettmer's report, it is reasonable to infer that our result of $2.1 \pm 0.3 \mathrm{~nm}$ indicates monolayer coverage. 


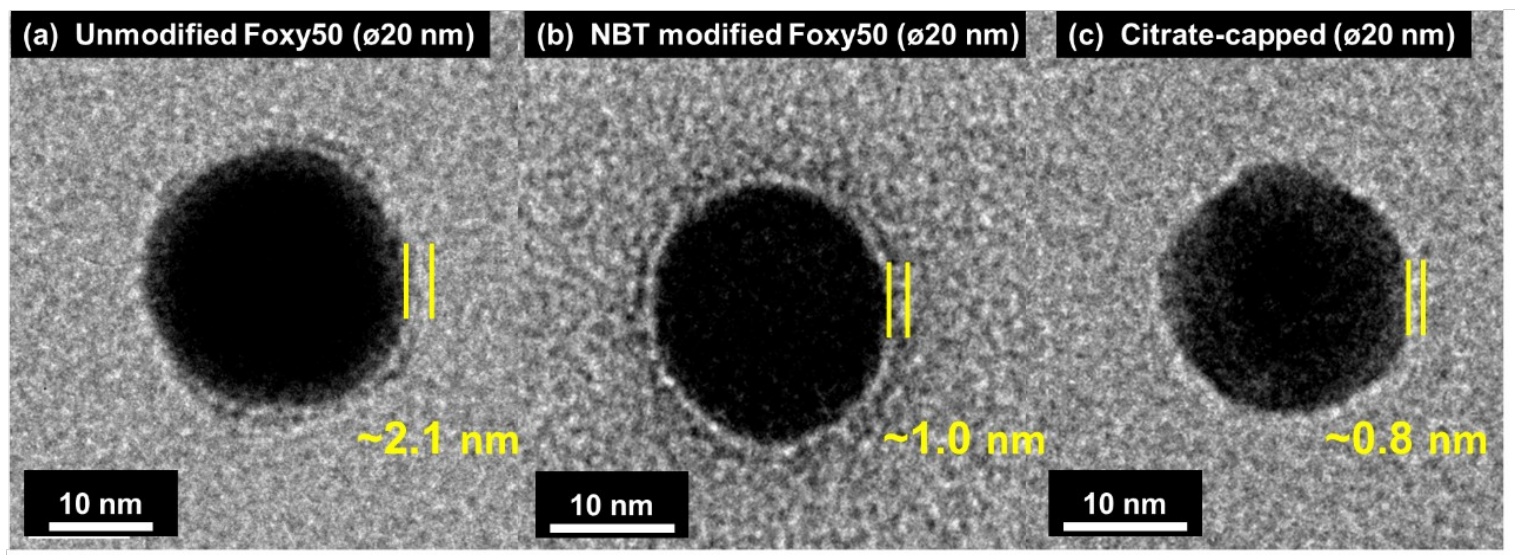




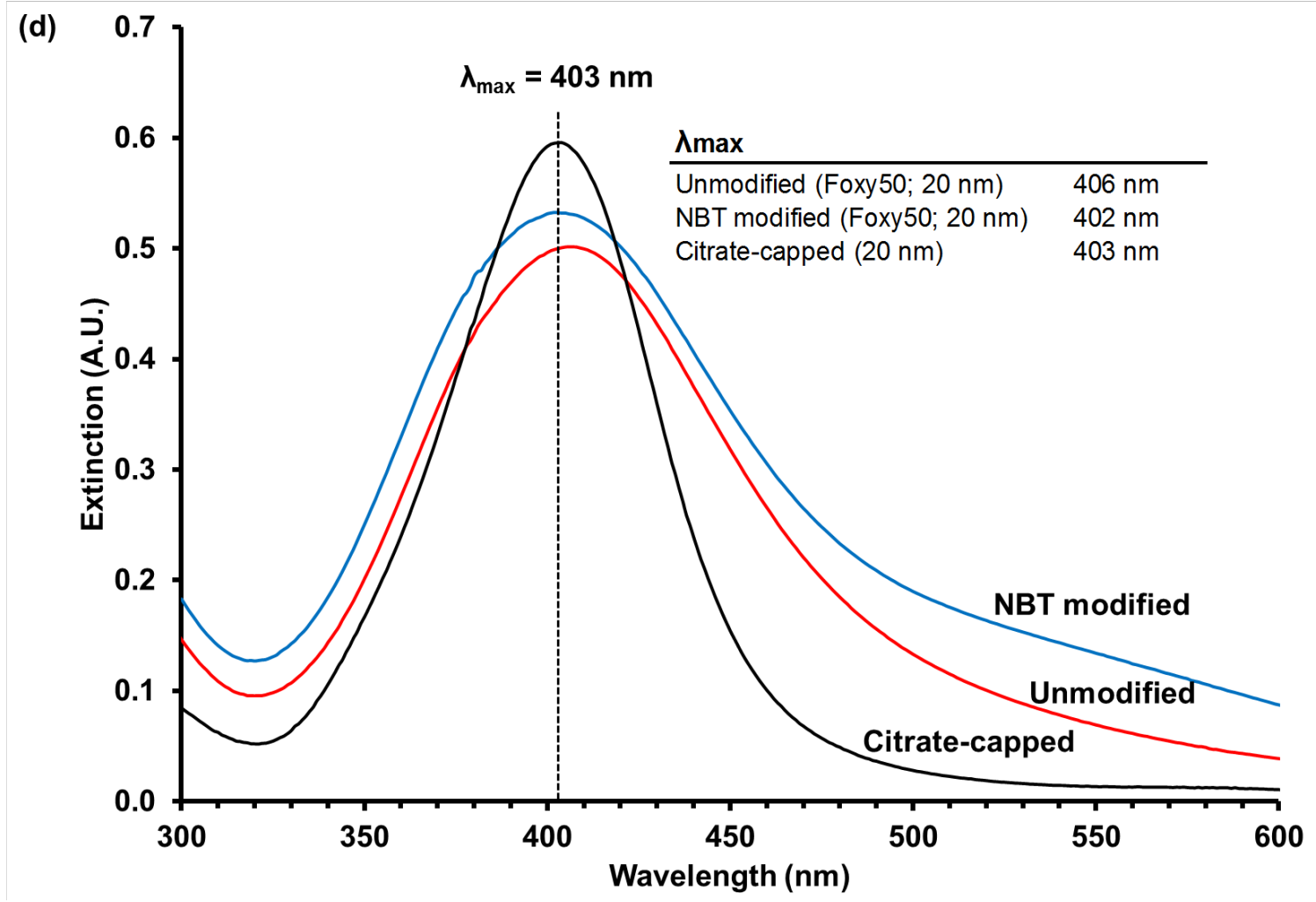

Figure 2. Characterization of biogenic silver nanoparticles $(\sim \varnothing 20 \mathrm{~nm})$ produced by Fusarium oxysporum 405 at $50^{\circ} \mathrm{C}$ (Foxy50) and commercial citrate-capped $(\sim \varnothing 20 \mathrm{~nm})$ silver nanoparticles. (a-c) Bright field transmission electron micrographs show the differences in surface layer thickness of unmodified biogenic silver nanoparticles, modified biogenic silver nanoparticles with $5 \mathrm{mM}$ nitrobenzene thiol (NBT), and commercial citratecapped silver nanoparticles. (d) Extinction plot demonstrating the relative localized surface plasmon resonance (SPR) peak position of the two biogenic nanoparticle preparations (unmodified and modified with NBT) in comparison to commercial citrate-capped nanoparticles. For biogenic silver nanoparticles, a $1 \mathrm{mM} \mathrm{AgNO}_{3}$ solution was added to Fusarium oxysporum 405 and incubated in the dark with shaking at 100 rpm for 3 days. The extinction maximum $\left(\lambda_{\max }\right)$ for each spectrum is listed on the right.

Effect of the layer structure and thickness on the extinction spectra is shown in Figure $2 \mathrm{~d}$ corresponding to the TEM measurements is discussed below for $\sim \varnothing 20 \mathrm{~nm}$ nanoparticles. All three spectra contain a single LSPR band with maximum absorbances at 406, 402, and $403 \mathrm{~nm}$, respectively. These spectra show no evidence of aggregation. Although the width of the bands of both unmodified B-AgNPs (FWHM 106 nm) and NBT modified B-AgNPs (FWHM $\sim 118 \mathrm{~nm}$ ) are greater than those of commercial, chemically 
produced AgNPs (FWHM $\sim 68 \mathrm{~nm}$ ); analyses discussed below (Table 1) indicates that the polydispersity of biogenic AgNPs is consistent with commercial AgNPs. Thus, we attribute the breadth of the extinction band more to the surface layer and less to polydispersity. In the case of NBT modified B-AgNPs, the width of the band is greater than the unmodified BAgNPs (FWHM $\Delta \sim 12 \mathrm{~nm}$ ). We suspect an increase in bandwidth of $\sim 12 \mathrm{~nm}$ is due to displacement of native layer with NBT and subsequent adsorption of free biomolecules in in a competitive manner for the NP surface, which may also explain the shift in peak position. According to Mie theory, ${ }^{45-46}$ modification of the nanoparticle surface with organic molecules will change the dielectric constant of the medium affecting the LSPR band position. As seen in Figure 2d, LSPR peak position of NBT modified B-AgNPs is blue shifted by $4 \mathrm{~nm}$. This indicates a change in the dielectric environment immediately surrounding the B-AgNPs, which is likely due to desorption of the protein corona. Jain and co-workers reported a similar blue shift observation when they desorbed the protein corona of AgNPs produced by Aspergillus species NJPO2 by SDS boiling. ${ }^{47}$

The absolute magnitudes of the extinction bands are not consistent. This likely due to a higher starting concentration of commercial citrate capped nanoparticles compared to biogenic nanoparticles. We attempted to achieve similar concentrations by diluting citrate nanoparticles by four-fold and biogenic nanoparticles two-fold. 
Table 1. Summary of calculated surface layer thicknesses and experimental measurements taken from extinction spectroscopy, TEM images, dynamic light scattering, polydispersity, and $\zeta$ potential for $\sim \varnothing 20 \mathrm{~nm}$ silver nanoparticles: unmodified biogenic (unmodified Foxy50), nitrobenzene thiol modified biogenic (NBT modified Foxy50), and commercial citrate-capped.

\begin{tabular}{|c|c|c|c|c|c|c|c|}
\hline & $\begin{array}{l}\text { LSPR } \\
\text { peak }\left(\lambda_{\max }\right. \\
\text { nm) }\end{array}$ & $\begin{array}{l}\text { Calculated } \\
\text { monolayer } \\
\text { film } \\
\text { thickness } \\
(\mathbf{n m})\end{array}$ & $\begin{array}{l}\text { TEM film } \\
\text { thickness } \\
(\mathbf{n m})^{\mathrm{b}}\end{array}$ & $\begin{array}{c}\text { TEM } \\
\text { diameter } \\
(\mathbf{n m})\end{array}$ & $\begin{array}{l}D_{\text {hyd }} \\
(\mathrm{nm})^{\mathrm{e}}\end{array}$ & $\begin{array}{l}\text { Polydispersity } \\
\text { index }\end{array}$ & $\begin{array}{c}\zeta \\
\text { potential } \\
(\mathrm{mV})^{\mathrm{g}}\end{array}$ \\
\hline $\begin{array}{l}\text { Unmodified } \\
\text { Foxy50 }(20 \mathrm{~nm})\end{array}$ & 406 & Unknown & $2.1 \pm 0.3$ & $17 \pm 3^{c}$ & $52 \pm 1$ & $0.4 \pm 1$ & $-24 \pm 1$ \\
\hline $\begin{array}{l}\text { NBT modified } \\
\text { Foxy50 }(20 \mathrm{~nm})\end{array}$ & 402 & $0.6-0.9^{a}$ & $1.0 \pm 0.1$ & $21 \pm 5^{c}$ & $57 \pm 2$ & $0.4 \pm 1$ & $-2 \pm 1$ \\
\hline $\begin{array}{l}\text { Citrate-capped } \\
(20 \mathrm{~nm})\end{array}$ & 403 & $0.8^{a}$ & $0.8 \pm 0.1$ & $21 \pm 3^{d}$ & $21 \pm 1$ & $0.4 \pm 1$ & $-33 \pm 3$ \\
\hline
\end{tabular}

\footnotetext{
${ }^{a}$ Theoretical values for a monolayer thickness are based on reported values on $\mathrm{Au}$ substrates.

${ }^{\mathrm{b}}$ Values reported are average based on three individual nanoparticles with six measurements per nanoparticle \pm standard deviation.

${ }^{\mathrm{c}}$ Transmission electron micrographs were analyzed with Gatan Digital Micrograph v2.31.734.0 or ImageJ 1.51t..${ }^{48}$ Values reported are an average \pm standard deviation. ${ }^{\mathrm{d}}$ According to manufacturer's specifications.

${ }^{\mathrm{e}}$ Hydrodynamic diameter (Z-average) based on intensity. Values reported are an average of three measurements \pm standard deviation.

${ }^{\mathrm{f}}$ Values reported are the mean of three measurements \pm standard deviation.

${ }^{g}$ Values reported are an average of three measurements \pm standard deviation at $25^{\circ} \mathrm{C}$. Measurement were conducted at neutral $\mathrm{pH}(\sim 7)$. $\mathrm{pH}$ values determined by Whatman $\mathrm{pH}$ indicator paper (Type CF, $\mathrm{pH}$ 0-14).
}

Table 1 summarizes theoretical monolayer thickness calculations along with our measurements obtained from extinction spectroscopy, TEM, DLS, polydispersity indices, and surface potential for the series of three $\sim \varnothing 20 \mathrm{~nm}$ AgNPs described above. In terms of calculated thickness values, we chose to make an indirect correlation to Au substrates since values for Ag substrates have not been reported. Our measured thicknesses for NBT modified B-AgNPs and citrate-capped AgNPs are consistent with values previously reported 
for Au substrates. For native B-AgNPs, we are unable to accurately report a calculated film layer thickness. This may vary considering the biological matrix that the nanoparticles are within, size of the nanoparticles, surface potential, the evolution of the biomolecular films, and the thickness calibration.

Our measurement of the film thickness is $2.1 \pm 0.3 \mathrm{~nm}$. The standard deviation provides an indication on the variability in layer thickness seen in Figure 2a. Less variability is observed in the thiol modified layer and citrate-capped AgNPs. Dynamic light scattering and zeta potential measurements were also used to further characterize the physical and chemical properties of AgNPs. Table 1 contains physical characterization results of particle size, polydispersity indices, surface potential, and relative colloidal stability.

Examining the DLS-measured hydrodynamic diameters, our results are consistent our previous report ${ }^{4}$ stating that the hydrodynamic diameter for both B-AgNPs is $\sim 3$ times larger than the TEM results ( $17 \pm 3 \mathrm{~nm}$ for unmodified) compared to citrate-capped AgNPs. As we stated in our earlier report, we believe this difference reflects the presence of a unique capping layer formed around B-AgNPs. Table 1 also shows the results of all AgNPs possessing a native surface potential ranging from approximately -2 to $-33 \mathrm{mV}$ at neutral pH. Consistent with previous results, ${ }^{4}$ the ZP values recorded for B-AgNPs were less negative than commercial AgNPs. A low ZP value of $-2 \mathrm{mV}$ recorded for NBT modified BAgNPs can be explained by displacement of ionized biomolecules by neutral NBT 
molecules; thus increasing the surface potential. Increase in ZP also suggests that the biomolecular layer is largely contributing to the surface potential. Despite a lower ZP value, NBT modified B-AgNPs were highly stable. We suspect that a fraction of biomolecules readsorbed to the NP surface after being initially displaced by NBT. We note NPs with Raman active molecules such as NBT that exhibit colloidal stability would be beneficial for studies involving Raman active NP-labels.

To identity putative proteins associated with AgNPs produced by F. oxysporum and estimate protein attributes of molecular weight and abundance. This established technique is based on the principle that proteins are separated by electrophoresis according to the protein's molecular weight (size) with larger proteins migrating slower and smaller proteins migrating faster. The result is typically a discrete band that can then be correlated to molecular weight standards to provide an estimate of protein size. ${ }^{49}$ There are a few reports that document the use of SDS-PAGE for the analysis of biogenic AgNPs from fungi, ,7- $^{2}$ 
${ }^{28}$ including F. oxysporum..$^{50}$ However no reports have systematically examined B-AgNPs ranging in sizes produced over a range of temperatures by F. oxysporum. We examined three sets of samples produced from F. oxysporum corresponding to three different temperature conditions (i.e., $45^{\circ} \mathrm{C}$, Foxy $45 ; 50^{\circ} \mathrm{C}$, Foxy50; and $75^{\circ} \mathrm{C}$, Foxy 75 ). Temperature conditions inversely correlate to nanoparticle diameters (i.e., $\sim \varnothing 30 \mathrm{~nm}, \sim \varnothing 20 \mathrm{~nm}$, and $ø 10 \mathrm{~nm}$, respectively) and directly correlate to protein synthesis levels (i.e., generally higher abundance of proteins at higher temperatures). Each sample set included two controls that were originally used during NP synthesis, 1\% YPG media and fungal filtrate (fungal culture without $\mathrm{AgNO}_{3}$ ). These controls were treated the same as $\mathrm{AgNO}_{3}$ exposed cultures. Figure 3 shows a representative image of a $12 \%$ SDS-PAGE gel showing the most abundant proteins/peptides resolved by analyzing a set of samples corresponding to three different incubation condition and NP size. The 1\% YPG media control lanes in all three cases principally shows a single band $\sim 10 \mathrm{kDa}$ in Figures 3A, 3D, and 3G. This result can be explained by $\sim 12 \%$ of peptone, the major protein source in YPG medium, consists of 5-10 $\mathrm{kDa}$ peptides with the remaining $\sim 88 \%$ consisting of smaller peptides..$^{51}$ Figures $3 \mathrm{~B}, 3 \mathrm{E}$, and $3 \mathrm{H}$ show fungal filtrate in the absence of $\mathrm{AgNO}_{3}$. Three bands at $\sim 100 \mathrm{kDa}, \sim 24 \mathrm{kDa}$, and $\sim 9 \mathrm{kDa}$ are evident for both Foxy45 and Foxy50; however Foxy75 (Figure 3H) has a single band at $\sim 9 \mathrm{kDa}$. Given the temperature condition of $75^{\circ} \mathrm{C}$, it is likely that larger proteins have degraded to short chain polypeptides as evidenced by the polypeptide staining pattern (i.e., smear) seen in Figure 3. In the case of Foxy 45 and Foxy50, we note the possibility of two starred bands at $\sim 47 \mathrm{kDa}$ (Figure 3B) and $\sim 35 \mathrm{kDa}$ (Figures $3 \mathrm{C}$ and 3E) in low abundance. Although these bands are faint, they may be consistent with a $\sim 44$ kDa nitrate reductase reported by Kumar et al. working with F. oxysporum ${ }^{52}$ and a $\sim 25 \mathrm{kDa}$ 
( $36 \mathrm{kDa}$ molecular weight resolved by LC-MS/MS) glyceraldehyde-3-phosphate reported by Zhang et al. also working with F. oxysporum. $\cdot \frac{50}{}$ For samples containing AgNPs, the most notable result is the enriched band between $\sim 2 \mathrm{kDa}$ and $\sim 5 \mathrm{kDa}$ seen in Figures $3 \mathrm{C}$ and $3 \mathrm{~F}$ for Foxy 45 and Foxy50, respectively. This band for Foxy75 is less pronounced (Figure 3I). Our results show that this enriched band is specific to the production of AgNPs considering all fungal cultures were treated equally except for $\mathrm{AgNO}_{3}$ addition. In comparing fungal cultures with and without $\mathrm{AgNO}_{3}$ exposure there are two important results. First, a $\sim 24$ $\mathrm{kDa}$ band consistent between filtrate (Figures 3B and 3E) and the AgNPs (Figures $3 \mathrm{C}$ and $3 \mathrm{~F}$ ), suggesting constitutive expression. Second, is a $\sim 100 \mathrm{kDa}$ band that appears to be in less abundance for the AgNPs (Figures $3 \mathrm{C}$ and $3 \mathrm{~F}$ ) compared to the filtrate (Figures 3B and $3 \mathrm{E})$, suggesting down-regulation or inhibition. With Foxy75 it is difficult to draw conclusions since the temperature condition $\left(75^{\circ} \mathrm{C}\right)$ is not ideal for protein stability. However, the stronger band intensity seen in Figures 3H and 3I for $\sim 9 \mathrm{kDa}$ supports the notion of increased protein abundance at higher temperatures based on higher staining intensity with increasing protein/peptide abundance. Though Foxy50 and Foxy75 are the predominantly investigated in this paper, we report results for Foxy 45 as we plan to use NPs from this temperature condition for our future surface-enhanced Raman spectroscopy (SERS) based immunoassay studies. Subsequent papers will report further details on AgNP modification and application. 


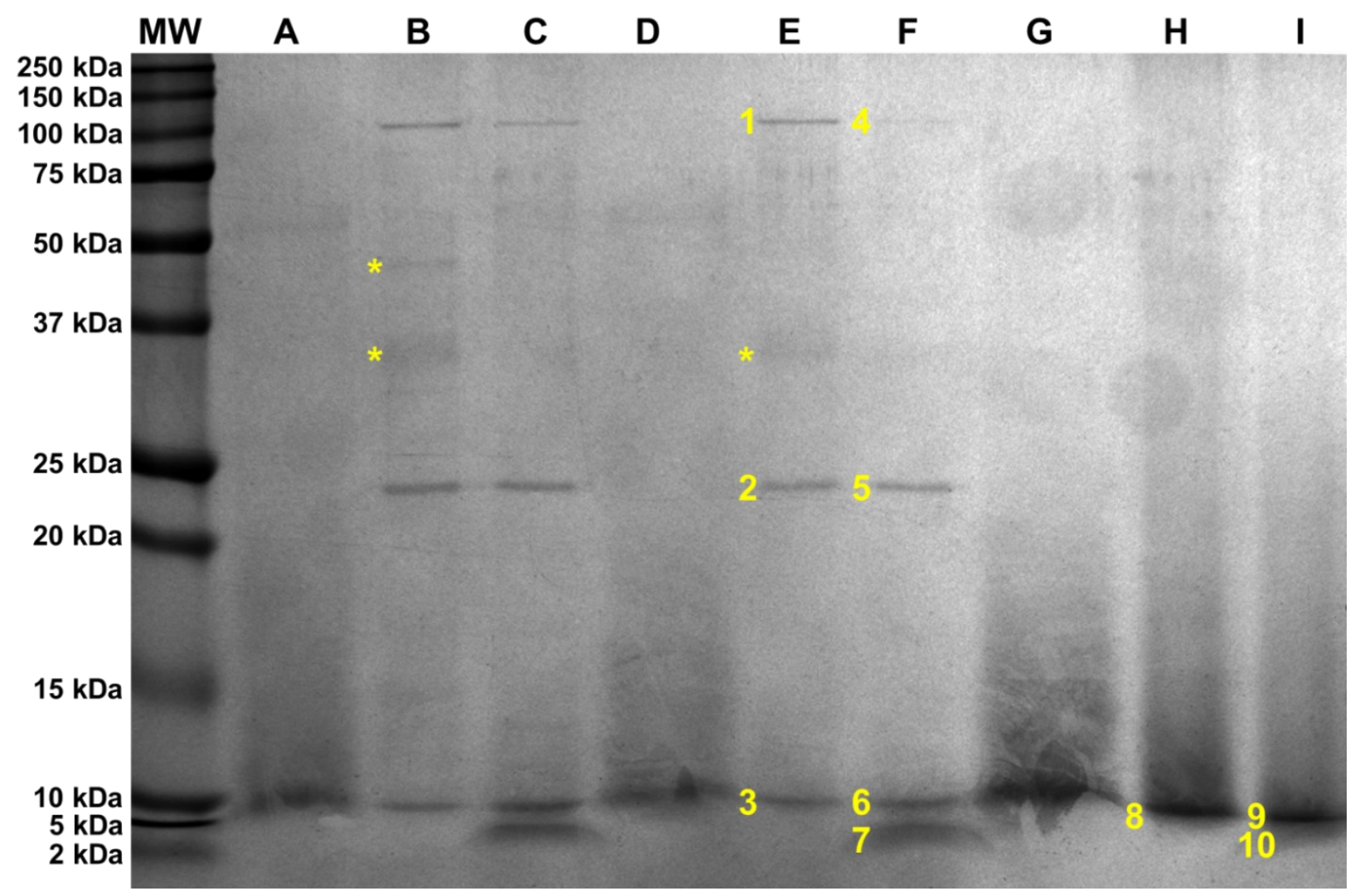

Figure 3. Representative grayscale image of a 1-D 12\% sodium dodecyl sulfate polyacrylamide gel with proteins/peptides profiles associated with the production of silver nanoparticles by Fusarium oxysporum (Foxy) at $45^{\circ} \mathrm{C}, 50^{\circ} \mathrm{C}$, and $75^{\circ} \mathrm{C}$. Lane (A) Foxy $451 \%$ yeast-peptone-glucose media control. Lane (B) Foxy 45 fungal filtrate without $1 \mathrm{mM} \mathrm{AgNO}{ }_{3}$. Lane (C) Foxy 45 with $1 \mathrm{mM} \mathrm{AgNO}_{3}$ exposure resulting in silver nanoparticles $(\varnothing 30 \mathrm{~nm})$. Lane (D) Foxy50 1\% yeast-peptone-glucose media control. Lane (E) Foxy50 fungal filtrate without $1 \mathrm{mM} \mathrm{AgNO}_{3}$. Lane (F) Foxy 45 with $1 \mathrm{mM} \mathrm{AgNO3} \mathrm{exposure} \mathrm{resulting} \mathrm{in} \mathrm{silver}$ nanoparticles $(\varnothing 20 \mathrm{~nm})$. Lane (G) Foxy75 1\% yeast-peptone-glucose media control. Lane (H) Foxy75 fungal filtrate without $1 \mathrm{mM} \mathrm{AgNO}_{3}$. Lane (I) Foxy75 with $1 \mathrm{mM} \mathrm{AgNO}$ exposure resulting in silver nanoparticles $(ø 10 \mathrm{~nm})$. MW represents molecular weight standards. The numbered bands correspond to excised bands that were further analyzed using ESI-LC-MS/MS. Stars (*) indicate possible bands in low abundance.

For protein identification, the numbered bands shown in Figure 3 were excised, trypsin-digested, and analyzed by LC-MS/MS. Table 2 lists the most abundant proteins identified based on extensive homology from the gel-extracted bands. Figure S1 in our supporting information contains the tandem mass spectra of the highest Mascot peptide scores for the corresponding gel-extracted bands. Peptide sequences were confirmed by 
tandem mass spectra providing evidence of high signal intensities and consistent peptide fragments ( $\mathrm{b}$ and y ions) shown in Figure S1. Discrepancy between the estimated molecular weights seen in Figure 3 compared to the molecular weights obtained from the NCBI database noted in Table 2 may be attributed to either post-translational modification (e.g., glycosylation or phosphorylation), post-translational cleavage, or splice variants by $F$. oxysporum. In analyzing the results contained in Table 2 , bands 1 and $4(\sim 100 \mathrm{kDa})$ were both identified as a catalase-peroxidase 2 protein from F. oxysporum. Identification of a catalase-peroxidase enzyme result supports previous reports purporting the involvement of a reductase enzyme in $F$. oxysporum. ${ }^{20,} \underline{25}$ We also suspect catalase-peroxidase enzyme(s) play a major role in studies that demonstrate AgNPs production using fungal culture filtrate. Catalase-peroxidase is an enzyme commonly found in virtually all aerobic organisms and functions to decompose $\mathrm{H}_{2} \mathrm{O}_{2}$ to water and molecular oxygen. $\frac{53}{3}$ This enzyme is among a class of antioxidants that are involved in counterbalancing reactive oxygen species (ROS) and defend the organism from exceeding oxidative stress. $\stackrel{53}{5}$ Sun et al. confirm catalase-peroxidase enzymes are involved in ion transport and metabolism and respond to oxidative stress in F. oxysporum; which may contribute to higher virulence in banana wilt disease. $\stackrel{54}{~ R e a c t i v e ~ o x y g e n ~ s p e c i e s ~ s u c h ~ a s ~ h y d r o g e n ~ p e r o x i d e ~}\left(\mathrm{H}_{2} \mathrm{O}_{2}\right)$ and superoxide anion $\left(\mathrm{O}_{2}{ }^{-}{ }^{-}\right)$are a group of free radicals, reactive molecules, and ions that are by-products of normal metabolism produced by partial reduction of oxygen during respiration. $\frac{55-56}{5}$ 
Table 2. Identification of the most abundant proteins from excised bands separated by sodium dodecyl sulphate polyacrylamide gel electrophoresis

\begin{tabular}{|c|c|c|c|c|c|c|}
\hline $\begin{array}{l}\text { Gel band \#; } \\
\text { Molecular } \\
\text { weight }\end{array}$ & Description & $\begin{array}{l}\text { Mascot } \\
\text { protein } \\
\text { score }^{a}\end{array}$ & $\begin{array}{c}\text { Mascot } \\
\text { threshold }\end{array}$ & $\begin{array}{c}\text { Protein } \\
\text { identification }\end{array}$ & $\begin{array}{l}\text { Molecular } \\
\text { weight (Da) }\end{array}$ & $\begin{array}{c}\text { NCBI } \\
\text { accession } \\
\text { number }^{d}\end{array}$ \\
\hline $1 ; \sim 100 \mathrm{KDa}$ & $\begin{array}{l}\text { Fungus control, } \\
\text { Foxy50 }\end{array}$ & 290 & $>54$ & $\begin{array}{l}\text { Catalase-peroxidase } 2 \\
\text { [Fusarium oxysporum } \\
\text { forma specialis cubense] }\end{array}$ & 85264 & 477517042 \\
\hline $2 ; \sim 24 \mathrm{KDa}$ & $\begin{array}{l}\text { Fungus control, } \\
\text { Foxy50 }\end{array}$ & --- & --- & $\begin{array}{l}\text { Low mass peptides } \\
\text { resulted in no protein } \\
\text { matches }\end{array}$ & --- & --- \\
\hline $3 ; \sim 9 \mathrm{KDa}$ & $\begin{array}{l}\text { Fungus control, } \\
\text { Foxy50 }\end{array}$ & 57 & $>54$ & $\begin{array}{l}\text { Hypothetical protein } \\
\text { FOXB_11747 [Fusarium } \\
\text { oxysporum Fo5176] }\end{array}$ & 19699 & 342876063 \\
\hline 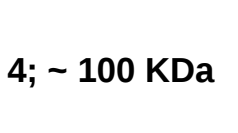 & $\begin{array}{l}\sim \varnothing 20 \mathrm{~nm} \\
\text { AgNPs, Foxy50 }\end{array}$ & 58 & $>52$ & $\begin{array}{l}\text { Catalase-peroxidase } 2 \\
\text { [Fusarium oxysporum } \\
\text { forma specialis cubense] }\end{array}$ & 86036 & 477514144 \\
\hline $5 ; \sim 24 \mathrm{KDa}$ & $\begin{array}{l}\sim \varnothing 20 \mathrm{~nm} \\
\text { AgNPs, Foxy50 }\end{array}$ & 95 & $>54$ & $\begin{array}{l}\text { Superoxide dismutase, } \\
\text { [Fusarium oxysporum } \\
\text { forma specialis cubense] }\end{array}$ & 23229 & 475668421 \\
\hline $6 ; \sim 9 \mathrm{KDa}$ & $\begin{array}{l}\sim \varnothing 20 \mathrm{~nm} \\
\text { AgNPs, Foxy50 }\end{array}$ & 136 & $>53$ & $\begin{array}{c}\text { Ubiquitin C [Fusarium } \\
\text { oxysporum Fo47] }\end{array}$ & 25731 & 587693765 \\
\hline $7 ; \sim 3 \mathrm{KDa}$ & $\begin{array}{l}\sim \varnothing 20 \mathrm{~nm} \\
\text { AgNPs, Foxy50 }\end{array}$ & --- & --- & $\begin{array}{l}\text { Low mass peptides } \\
\text { resulted in no protein } \\
\text { matches }\end{array}$ & --- & --- \\
\hline $8 ; \sim 9 \mathrm{KDa}$ & $\begin{array}{l}\text { Fungus control, } \\
\text { Foxy } 75\end{array}$ & --- & --- & $\begin{array}{l}\text { Low mass peptides } \\
\text { resulted in no protein } \\
\text { matches }\end{array}$ & --- & --- \\
\hline 9; $9 \mathrm{KDa}$ & $\begin{array}{l}\sim \varnothing 10 \mathrm{~nm} \\
\text { AgNPs, Foxy75 }\end{array}$ & 126 & $>53$ & $\begin{array}{c}\text { Ubiquitin C [Fusarium } \\
\text { oxysporum Fo47] }\end{array}$ & 25731 & 587693765 \\
\hline $10 ; \sim 3 \mathrm{KDa}$ & $\begin{array}{l}\text { ø10 nm } \\
\text { AgNPs, Foxy75 }\end{array}$ & --- & --- & $\begin{array}{l}\text { Low mass peptides } \\
\text { resulted in no protein } \\
\text { matches }\end{array}$ & --- & --- \\
\hline
\end{tabular}

\footnotetext{
${ }^{a}$ Protein ion score is $-10^{*} \log (P)$, where $P$ is the probability that the observed match is a random event

${ }^{\mathrm{b}}$ Individual ion scores above threshold indicate identity or extensive homology at $P<0.05$

${ }^{\mathrm{c}}$ Identification based on most extensive homology to abundant protein

${ }^{\mathrm{d}}$ National Center for Biotechnology Information (NCBI) Protein database
} 
Aguirre et al. explain in the presence of trace metal ions, $\mathrm{O}_{2}{ }^{-}$can react with $\mathrm{H}_{2} \mathrm{O}_{2}$ and generate a more reactive singlet oxygen species $\left({ }^{1} \mathrm{O}_{2}\right)$. In addition to reactive metal ions, ROS production can increase in fungi due to various stress factors such as starvation, ionizing irradiation, ultra-violet irradiation, visible light, temperature extremes, $\mathrm{pH}$ extremes, medium osmolality, mechanical damage, and interactions with other living organisms. ${ }^{\frac{53}{}}$ Hydrogen peroxide, a major ROS and signalling molecule, ${ }^{57}$ leads to the production of hydroxyl radical (HO'), which can oxidase virtually any cellular molecule; causing DNA damage, protein inactivation, protein cross-linking and fragmentation, and lipid peroxidation. $\frac{55}{}$ Thus, at high concentrations of ROS, damage to biomolecules occurs, which may serve to be protective against interspecies competition; whereas, low/moderate concentrations of ROS serve as intracellular signalling molecules regulating physiological responses and developmental processes in fungi ${ }^{\frac{53}{3}}$ and plants. $\frac{56}{}$ As F. oxysporum is commonly considered to be a plant pathogen, hence mechanisms for regulating ROS concentrations within fungi and plants may have co-evolved, since plants are known to produce an oxidative burst ${ }^{58}$ in response to fungal structures or activity. ${ }^{59}$ Redundancy in ROS proteins may also explain relative abundance of ROS proteins detected in Figure 3. As noted above, qualitative comparison between bands 1 and 4 (Figure 3 ) suggests a decrease in abundance in fungal cultures exposed to $\mathrm{AgNO}_{3}$ (Figures 3E and 3F). Gavanji and coworkers report that catalase enzymes may be inhibited by high concentrations of hydrogen peroxide in context of elevated reactive oxygen species (ROS). $\stackrel{60}{ }$ Band $2(\sim 24 \mathrm{kDa})$ and Band $3(\sim 9 \mathrm{kDa})$ shown in Table 2 provide little information with low mass peptides (Table 2, Band 2) and a hypothetical protein from F. oxysporum (Table 2, Band 3). However, in examining the record contained within the NCBI database for the $\sim 9 \mathrm{kDa}$ hypothetical 
protein (Band 3), this protein is phylogenetically clustered with other mitogen-activated protein (MAP) kinase kinase proteins from fungi, including F. oxysporum. ${ }^{61}$ Mitogenactivated protein kinase cascades are evolutionarily conserved proteins in eukaryotic cells that are involved in transducing a variety of extracellular signals and regulating growth and differentiation processes. $\underline{62}$ We provide further discussion on MAP kinase cascades below. Band $5(\sim 24 \mathrm{kDa})$ shown in Table 2 is identified to be consistent with superoxide dismutase (SOD) from F. oxysporum. Though we did not identify the adjacent band in the fungus control (Table 2, Band 2), we suspect a similar protein with SOD activity. Like catalase-peroxidase enzymes, SOD proteins have antioxidant activity in regulating oxidative stress. $\frac{53}{}$ SOD enzymes catalyzes dismutation of superoxide anion $\left(\mathrm{O}_{2}{ }^{-}\right)$producing $\mathrm{H}_{2} \mathrm{O}_{2}$ and $\mathrm{O}_{2}$. As Gessler et al. report, $\mathrm{O}_{2}{ }^{-}$can be produced by $\mathrm{O}_{2}$ reduction with an NADPH catalyzed oxidase. $\frac{53}{}$ This would be consistent with Durán et al. mechanistic proposal of B-AgNPs production involving the reduction of NADP+ to NADPH and oxidization of $\mathrm{NO}_{3}{ }^{-}$to $\mathrm{NO}_{2} \cdot{ }^{-20}$ SOD enzymes believed to be the first line of defense against oxidative stress in eukaryotic cells, $\underline{53}$ which would explain expression in both fungal cultures exposed (Figure 3E; Table 2) and not exposed to $\mathrm{AgNO}_{3}$ (Figure 3F; Table 2). From an ecological perspective, an abundance of SOD enzymes can serve to be protective during saprobic growth or can serve to be a competitive (i.e., virulence) factor in colonizing a plant host. For example, a $24 \mathrm{kDa}$ protein from Fusarium oxysporum culture filtrates has been reported by Bailey and coworkers. Activity of this protein has been ascribed to eliciting ethylene production and necrosis in coca leaves. $\frac{63}{3}$ We speculate that this $24 \mathrm{kDa}$ protein is involved in the ROS, possibly having SOD activity resulting $\mathrm{H}_{2} \mathrm{O}_{2}$ production; which would be consistent with our conclusions. Thus, it is reasonable to infer F. oxysporum exposure to a solution of $\mathrm{AgNO}_{3}$ to 
produce AgNPs would lead to increased concentrations of ROS. This notion would be consistent with the observed protein profiles (Figure 3) and identification of highly abundant proteins (Table 2). Aguirre et al. comment that filamentous fungi [such as $F$. oxysporum] have additional mechanisms to handle ROS, such as the presence of a larger number of phosphorelay sensor kinases, antioxidant enzymes, and secondary metabolites with antioxidant properties. ${ }^{55}$ Bands 6 and $9(\sim 9 \mathrm{kDa})$ was consistently identified as ubiquitin (likely from the ubiquitin c gene, $\mathrm{UBC}^{\underline{64}}$ ) from F. oxysporum. Ubiquitin is a highly conserved regulatory protein ${ }^{65}$ that is widely expressed in eukaryotes and has a molecular weight of $8500 . \frac{66}{}$ Effects of ubiquitinylation include protein degradation, protein trafficking, cell-cycle regulation, DNA repair, apoptosis, and signal transduction..$\underline{64}$ For more details on ubiquitin function, please refer to Hershko and Ciechanover review on the ubiquitin system. $\frac{65}{}$ Ubiquitin has been reported to be one of the most abundant proteins in eukaryotic cells, however ubiquitin does not seem to be in excess, but rather regulated as a free pool of adequate levels contingent on cell conditions. ${ }^{64}$ Ubiquitin $C$ has been ascribed to the UBC gene in mammals that is responsive to UV irradiation, heat shock, oxidative stress, and translational impairment. ${ }^{64}$ Also, site-specific interactions between ubiquitin and gold nanoparticles have been reported. ${ }^{67}$ Collectively, these pieces of evidence support our inference of adaptive or stress responsive proteins are involved with silver ion exposure by F. oxysporum. For enriched bands seen in Figure 3 for Foxy50 (Band 7) and Foxy 75 (Band 10), mass spectrometric results yielded low mass peptides with no protein matched (Table 2). 


\section{Determination of the surface corona composition}

The direct characterization of the biomolecular composition of the corona involves a unique approach to desorb the surface corona using acetonitrile (Figure 1b) and analyzing the desorbed fraction using both MALDI-MS and LC-MS/MS. The experimental details of the desorption optimization are found in the SI. We found that desorption in $40 \%$ acetonitrile was optimal. This approach enabled us to interrogate the biomolecules associated with the NPs and provide information on the $\leq 5 \mathrm{kDa}$ enriched SDS-PAGE bands we observed in Figure 3. Our three-pronged characterization approach involved (1) MALDI-MS to confirm the molecular size range of all proteins associated with B-AgNPs; (2) LC-MS/MS for identification; and (3) NMR to investigate our suspicion of carbohydrates. We present our MALDI-MS and LC-MS/MS chromatograms and spectra in our supplementary section. Figures S3 and S4 contain our MALDI-MS and LC-MS/MS results for $\sim \varnothing 20 \mathrm{~nm}, \sim \varnothing 10 \mathrm{~nm}$, and the corresponding controls, respectively. Based on our MALDI-MS results shown in Figures S3a-d and S4a-d, we conclude that there are expected spectral differences among the samples and that the highest signals were recorded below 5 kDa. Future work may include tracking the origin the peptides and examining the influence of culture media. In context of $\mathrm{m} / \mathrm{z}$ signal similarities, the MALDI spectrum recorded from the acetonitrile desorbed layer is more consistent with the fungal control rather than that of the media (Figures S3 and S4). Our results suggest that the biomolecules associated with the corona primarily originate from F. oxysporum and not from the culture media (Figures 
S3 and S4). In terms of size ranges for MALDI analysis, we also tested ranges up to $20 \mathrm{kDa}$ and $220 \mathrm{kDa}$, however the signal to noise ratio was low suggesting low abundance (data not shown). Thus, our MALDI-MS provides evidence that the surface corona is composed largely of peptides. Next, we proceeded to identify the peptides in each sample by LCMS/MS. Figures S3e-h and S4e-h contain our base peak ion chromatograms (BPI) for acetonitrile treated $\sim ø 20 \mathrm{~nm}$ AgNPs and $\sim ø 10 \mathrm{~nm}$ AgNPs; supernatants of the 'as prepared' dispersions, fungus control (without $\mathrm{AgNO}_{3}$ ), and media control (1\% YPG). Consistent with MALDI-MS spectral differences among the samples, our BPI chromatograms show differences among samples. However, most peptides have short retention time $(\sim 5 \mathrm{~min})$ suggesting that there is a higher ratio of more polar than less polar peptides, which would be reasonable given that the NPs are dispersed in an aqueous medium. Figure S5 contains our tandem mass spectra and peptide sequences with the highest Mascot scores. Peptide sequences were confirmed by tandem mass spectra providing evidence of high signal intensities and consistent peptide fragments ( $b$ and $y$ ions) shown in Figure S5. 
Tables 3 and 4 contains the most abundant proteins identified with extensive homology for $\sim ø 20 \mathrm{~nm}$ and $\sim ø 10 \mathrm{~nm}$ AgNPs, respectively, based on tandem mass spectrometry. All proteins identified in the desorbed surface corona of both $\sim ø 20 \mathrm{~nm}$ and $\sim \varnothing 10 \mathrm{~nm}$ AgNPs are homologous to F. oxysporum (Tables 3 and 4). In Table 3 , phosphoenolpyruvate carboxykinase, glyceraldehyde-3-phosphate dehydrogenase, and malate dehydrogenase enzymes have been reported to be involved in carbohydrate transport and metabolism with co-enzyme nicotinamide adenine dinucleotide. $\frac{54,68}{6}$ Identification of elongation factor 2 suggests the abundance of a protein involved in protein synthesis (Table 3 ). The supernatant of $\sim ø 20 \mathrm{~nm}$ AgNPs contains phosphoenolpyruvate carboxykinase (Table 3). The abundance of phosphoenolpyruvate carboxykinase suggests that $F$ oxysporum is expressing proteins in high abundance involved in the generation of high energy molecules such as adenosine triphosphate (ATP). In comparison with Foxy50 fungal filtrate control, cultures exposed to $\mathrm{AgNO}_{3}$ have upregulated or have higher expression levels consistent with carbohydrate metabolism as evidenced by the hypothetical proteins from other fungal organisms shown in Table 2 . These results are consistent with the fractions derived $\sim \varnothing 10 \mathrm{~nm}$ AgNPs and the related Foxy75 controls (Table 4). Changes in relative protein abundance could be attributed to differences in production temperature $\left(50^{\circ} \mathrm{C}\right.$ versus $\left.75^{\circ} \mathrm{C}\right)$ and protein stability. For our medium control, we identified a peptide with extensive homology to Saccharomyces cerevisiae, which is consistent with the yeast extract component (Table 3). Low mass peptides resulting in no protein matches were found for the medium control for $\sim ø 10 \mathrm{~nm}$; likely due to protein degradation at $75^{\circ} \mathrm{C}$ (Table 4$)$. 
Table 3. Identification of the most abundant proteins based on extensive homology from $ø 20 \mathrm{~nm}$ silver nanoparticles or culture filtrate produced by Fusarium oxysporum at $50^{\circ} \mathrm{C}$.

\begin{tabular}{|c|c|c|c|c|c|}
\hline $\begin{array}{c}\text { Sample } \\
\text { description }\end{array}$ & $\begin{array}{l}\text { Mascot } \\
\text { protein } \\
\text { Score }^{a}\end{array}$ & $\begin{array}{l}\text { Mascot } \\
\text { threshold }\end{array}$ & Protein identification ${ }^{c}$ & $\begin{array}{l}\text { Molecular } \\
\text { weight } \\
\text { (Da) }\end{array}$ & $\begin{array}{c}\text { NCBI } \\
\text { accession } \\
\text { number }\end{array}$ \\
\hline \multirow[t]{4}{*}{$\begin{array}{l}\text { Desorbed } \\
\text { surface } \\
\text { corona from } \\
\varnothing 20 \mathrm{~nm} \\
\text { AgNPs }\end{array}$} & 302 & $>73$ & $\begin{array}{c}\text { Phosphoenolpyruvate } \\
\text { carboxykinase [F. oxysporum } \\
\text { forma specialis lycopersici] }\end{array}$ & 36980 & 902727943 \\
\hline & 135 & $>73$ & $\begin{array}{l}\text { Glyceraldehyde-3-phosphate } \\
\text { dehydrogenase } \\
\text { [F. oxysporum forma specialis } \\
\text { cubense] }\end{array}$ & 36085 & 475671174 \\
\hline & 116 & $>73$ & $\begin{array}{c}\text { Elongation factor } 2 \\
{[\text { F. oxysporum forma specialis }} \\
\text { lycopersici] }\end{array}$ & 50294 & $\underline{902732414}$ \\
\hline & 82 & $>73$ & $\begin{array}{l}\text { Malate dehydrogenase, } \\
\text { [F. oxysporum] }\end{array}$ & 31158 & 587669178 \\
\hline $\begin{array}{l}ø 20 \mathrm{~nm} \\
\text { AgNPs } \\
\text { supernatant }\end{array}$ & 113 & $>73$ & $\begin{array}{c}\text { Phosphoenolpyruvate } \\
\text { carboxykinase [F. oxysporum } \\
\text { forma specialis lycopersici] }\end{array}$ & 36980 & 902727943 \\
\hline \multirow[t]{2}{*}{$\begin{array}{l}\text { Foxy50 } \\
\text { fungus } \\
\text { control }^{\mathrm{e}}\end{array}$} & 282 & $>73$ & $\begin{array}{l}\text { Hypothetical protein } \\
\text { TGAM01_01851 } \\
\text { [Trichoderma gamsii] }\end{array}$ & 89417 & 969886537 \\
\hline & 80 & $>73$ & $\begin{array}{l}\text { Hypothetical protein, variant } \\
\text { [Magnaporthe oryzae] }\end{array}$ & 134233 & 389623189 \\
\hline $\begin{array}{l}\text { Medium } \\
\text { control }^{f}\end{array}$ & 163 & $>71$ & $\begin{array}{c}\text { YGR192C } \\
\text { [Saccharomyces cerevisiae] }\end{array}$ & 35666 & 45269553 \\
\hline
\end{tabular}

\footnotetext{
${ }^{\text {a }}$ Protein ion score is $-10^{*} \log (P)$, where $P$ is the probability that the observed match is a random event.

${ }^{\mathrm{b}}$ Individual ion scores above threshold indicate identity or extensive homology at $P<0.05$

${ }^{c}$ Identification based on most extensive homology to abundant protein

${ }^{\mathrm{d}}$ National Center for Biotechnology Information (NCBI) Protein database

${ }^{\mathrm{e}}$ Fungus cultured without $1 \mathrm{mM} \mathrm{AgNO}_{3}$

${ }^{\mathrm{f}} 1 \%$ yeast-peptone-glucose broth
} 
Table 4. Identification of the most abundant proteins based on extensive homology from $\varnothing 10 \mathrm{~nm}$ silver nanoparticles or culture filtrate produced by Fusarium oxysporum at $75^{\circ} \mathrm{C}$.

\begin{tabular}{|c|c|c|c|c|c|}
\hline $\begin{array}{l}\text { Sample } \\
\text { description }\end{array}$ & $\begin{array}{l}\text { Mascot } \\
\text { protein }^{\text {Score }}\end{array}$ & $\begin{array}{l}\text { Mascot } \\
\text { threshold }\end{array}$ & Protein identification $^{c}$ & $\begin{array}{l}\text { Molecular } \\
\text { weight } \\
\text { (Da) }\end{array}$ & $\begin{array}{c}\text { NCBI } \\
\text { accession } \\
\text { number }\end{array}$ \\
\hline $\begin{array}{l}\text { Desorbed } \\
\text { surface } \\
\text { corona from } \\
\text { ø10 nm } \\
\text { AgNPs }\end{array}$ & 84 & $>73$ & $\begin{array}{c}\text { Malate dehydrogenase, NAD- } \\
\text { dependent [Fusarium } \\
\text { oxysporum] }\end{array}$ & 34862 & 587669372 \\
\hline \multirow[t]{2}{*}{$\begin{array}{l}\emptyset 10 \mathrm{~nm} \\
\text { AgNPs } \\
\text { supernatant }\end{array}$} & 90 & $>73$ & $\begin{array}{l}\text { Hypothetical protein, variant } \\
\text { [Magnaporthe oryzae] }\end{array}$ & 134233 & 389623189 \\
\hline & 73 & $>73$ & $\begin{array}{c}\text { Putative serine } \\
\text { endopeptidase protein } \\
\text { [Eutypa lata] } \\
\end{array}$ & 101362 & 629667903 \\
\hline \multirow[t]{2}{*}{$\begin{array}{l}\text { Foxy75 } \\
\text { fungus } \\
\text { control }^{\mathrm{e}}\end{array}$} & 84 & $>73$ & $\begin{array}{l}\text { Hypothetical protein, variant } \\
\text { [Magnaporthe oryzae] }\end{array}$ & 134233 & $38962318 s$ \\
\hline & 75 & $>73$ & $\begin{array}{l}\text { Hypothetical protein } \\
\text { TGAM01_01851 } \\
\text { [Trichoderma gamsii] }\end{array}$ & 89417 & $\underline{969886537}$ \\
\hline $\begin{array}{l}\text { Medium } \\
\text { control }\end{array}$ & --- & --- & $\begin{array}{l}\text { Low mass peptides resulted } \\
\text { in no protein matches }\end{array}$ & -- & -- \\
\hline
\end{tabular}

${ }^{a}$ Protein ion score is $-10^{*} \log (P)$, where $P$ is the probability that the observed match is a random event.

${ }^{\mathrm{b}}$ Individual ion scores above threshold indicate identity or extensive homology at $P<0.05$

${ }^{\mathrm{c}}$ Identification based on most extensive homology to abundant protein

${ }^{\mathrm{d}}$ National Center for Biotechnology Information (NCBI) Protein database

${ }^{\mathrm{e}}$ Fungus cultured without $1 \mathrm{mM} \mathrm{AgNO}_{3}$

${ }^{\mathrm{f}} 1 \%$ yeast-peptone-glucose broth 
Our results profiling the composition of the surface corona is consistent with a previous report identifying glyceraldhehyde-3-phosphate dehydrogenase from $128 \pm 70 \mathrm{~nm}$ gold nanoparticles synthesized by F. oxysporum. $\frac{50}{}$ Zhang et al. also identified a 3-glucan binding protein that contrasts our results; however both proteins are consistent with carbohydrate metabolism. Sun et al. $\frac{54}{\text { reported }} 99$ proteins expressed by mainly two pathotypes (low and high virulence) of F. oxysporum that cause banana wilt. Based on the author's cluster analysis of orthologous groups of proteins, the largest functional

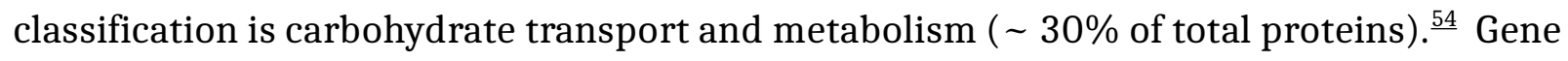
ontology analysis revealed that most of 99 proteins were involved in either processes related to carbohydrate metabolism or antioxidation..$^{54}$ Thus, the authors conclude that carbohydrate metabolism and ion transport may be important in the pathogenesis of Fusarium wilt disease in bananas. ${ }^{54}$ In an ecological context, high abundance of proteins involved in carbohydrate metabolism and ion transport for activating antioxidant molecules would be consistent with biotic and abiotic stress response.

Our in situ characterization and our direct characterization of the surface corona by acetonitrile desorption suggests that the peptides identified with extensive homology to proteins involved in either carbohydrate metabolism or responding to reactive oxygen species (i.e., anti-oxidation). We hypothesis that higher expression of proteins involved in carbohydrate metabolism or anti-oxidation are ultimately regulated by mitogen-activated protein (MAP) kinase cascades. Segorbe and co-workers ${ }^{69}$ describe MAP kinase cascades as a family of evolutionarily conserved three-tiered protein kinase modules composed of a 
MAP kinase kinase kinase (MAP3K) that phosphorylates downstream MAP kinase kinase (MAP2K), which activates a MAP kinase for downstream transmission of cellular signals and gene transcription. Phosphorylation occurs at the hydroxyl group of serine, threonine, and tyrosine residues. These evolutionarily conserved pathways in a variety of organisms

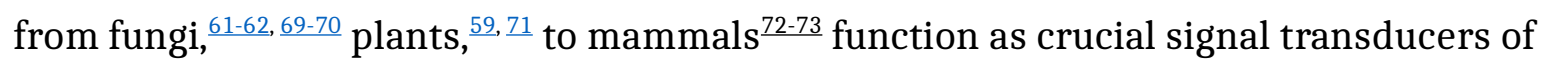
environmental stimulus, stress adaptation, and host recognition to activate gene transcription for cellular responses (e.g., apoptosis, proliferation, differentiation, defense). A previous report indicates that MAP kinases are associated with the regulation of physiological traits and virulence in banana wilt disease caused by F. oxysporum forma specialis cubense. $\frac{61}{}$ Recently, three MAP kinases Fmk1, Mpk1, and Hog 1 are involved in the regulation of development (e.g., hyphal growth, fusion, and aggregation), stress response (e.g., cell wall integrity, heat, hyperosmotic, oxidative), and virulence of $F$. oxysporum against plant and animal hosts. ${ }^{74}$ Segorbe and co-workers describe Mpk 1 and Hog 1 regulate cellular adaptation to different types of stress, whereas Fmk1 and Mpk1 jointly contribute to ROS homeostasis. Both processes impact fungal growth and affect virulence towards plants or animal hosts. ${ }^{69}$ Thus, our results leads us to conclude that the surface corona of BAgNPs produced by F. oxysporum is composed of peptides from adaptive or protective proteins likely responding to environmental stress. We postulate F. oxysporum is predominantly responding to reactive silver ions and to a lesser extent heat stress and upregulating expression of proteins involved in metal detoxification. Given that surface corona is composed of peptides, we suspect that the mechanism of $\mathrm{Ag}^{+}$ions reduction to AgNPs may be consistent with Kracht and co-workers ${ }^{75}$ report demonstrating AgNPs synthesis using peptide aggregates in the presence of chloride ions as a medium for 
electron transfer. We have previously shown an energy dispersive X-ray spectrum with a strong signal originating from chloride collected from spot profiles of AgNPs on fungal

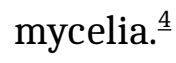

In another study investigating B-AgNPs from using culture filtrate of Aspergillus tubingensis, Ballottin and co-workers $\frac{76}{}$ identified eight proteins in situ from $\sim \varnothing 35 \mathrm{~nm}$ AgNPs by mass spectrometry. Based on the enzyme commission (EC) numbers provided in Ballottin et al. paper, three proteins identified were glucan 1,4-alpha-glucosidase (EC

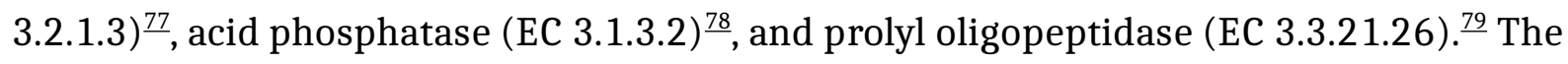
authors conclude that all proteins were involved in metabolic pathways and are important for carbon, phosphorus, and nitrogen uptake, and for fungal growth. Furthermore, the authors claim identified proteins are involved in the formation and stabilization of BAgNPs. Though we agree with Ballottin and co-workers that protein/peptides are involved in formation and stabilization of B-AgNPs, our identified proteins from F. oxysporum contrasts those of Ballottin's report. Though the studies examine different fungal organisms, we believe it is more important to evaluate the characterization approach for a fair comparison. Thus, we provide an explanation below in examining our characterization approaches of in situ versus a more direct investigation of the surface corona.

In examining our two characterization approaches (Figure 1), a few key points must be noted. Both approaches led to identifying peptides that have extensive homology to protective or adaptive proteins. However, the exact proteins identified through each 
approach were different. The difference can be explained by higher background protein expression levels in situ. As discussed above, $80-91 \%$ of total protein abundance is found in the supernatant after centrifuging AgNPs (Tables S1 and S2). Higher protein backgrounds affect the overall protein profile and careful interpretations must be made in context of the surface corona. Differences in protein abundance and protein profiles should be interpreted in context of the fungal culture conditions. For example, temperature conditions will influence protein expression levels and stability. Initial culture media may also play a role. Also, organism variability may influence specific proteins expressed, however we believe that most fungal proteins will lead to adaptive or protective proteins in the event of metal ion exposure. Thus, we encourage researchers investigating the surface corona of B-AgNPs to carefully document methods of characterization to enable appropriate treatment of the data for ecological interpretations.

We now turn our attention to our hypothesis of glycosylated proteins on the surface of B-AgNPs. Based on our discussion above related to post-translational modification of proteins in context of our SDS-PAGE results and our experience producing AgNPs, we hypothesized that a fraction of amino acid residues may be glycosylated. Wan and coworkers state that glycosylation is one of the most abundant post-translational protein modifications..$^{80}$ As such, we investigated the possibility of carbohydrates associated with the surface layer of B-AgNPs by one dimensional ${ }^{1} \mathrm{H}$ NMR. Figure 4 shows our ${ }^{1} \mathrm{H}$ NMR spectrum with signals collected at $\sim \delta 3.6$ and $\sim \delta 5.2 \mathrm{ppm}$ consistent with carbohydrates, likely anomeric resonances of glucose $\cdot \stackrel{81}{ }$ Further investigation using 2D NMR and possibly 
coupled with liquid chromatography may help identify the carbohydrates more definitely. The broad bands with densely crowded resonance lines seen between $\sim \delta 1.2, \sim \delta 3.8, \sim \delta$ 7.3, and $\sim \delta 8.0 \mathrm{ppm}$ are consistent with proteins. ${ }^{82}$ Currently, there are no reports of the surface corona of B-AgNPs being comprised of carbohydrates. We are the first to provide evidence of surface corona composed of peptides and carbohydrates. The implications for carbohydrates is broader modification strategies, role in colloidal stability,, possible effect on nanoparticle size/morphology, ${ }^{83}$ use as effective capping agents, $\stackrel{84.86}{ }$ and influencing nanoparticle-cell interactions either by enhancing cell membrane adhesion and uptake or stimulating the immune system in humans. ${ }^{.0}$ 


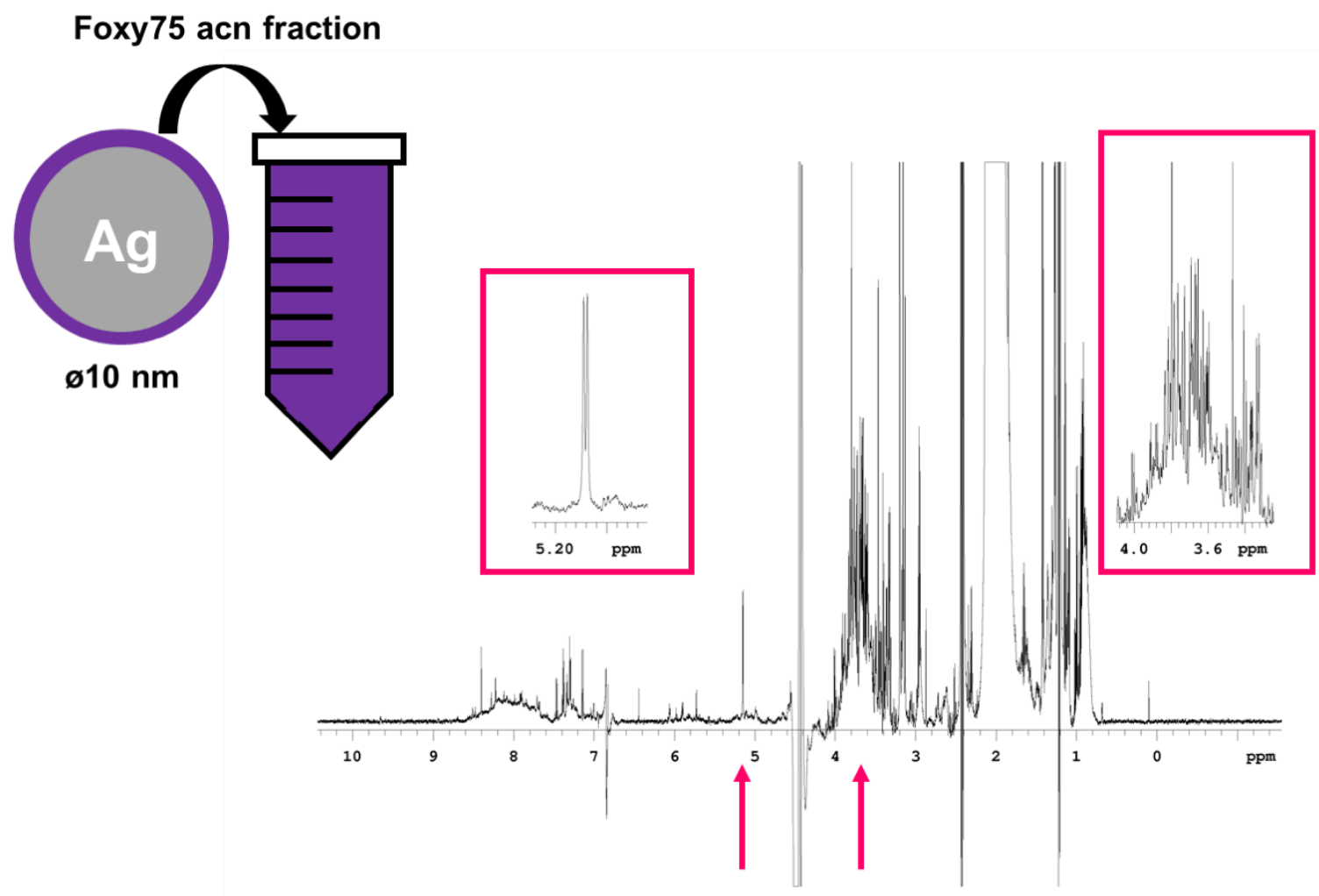

Figure 4. ${ }^{1} \mathrm{H}$ Nuclear magnetic resonance spectrum collected from an acetonitrile fraction containing the desorbed surface layer (purple in cartoon) of $\sim ø 10 \mathrm{~nm}$ silver nanoparticles produced by Fusarium oxysporum in heavy water (i.e., deuterium oxide). Highlighted regions (pink arrow and boxes) show signals consistent with carbohydrates, likely anomeric resonances of glucose. Signals for deuterium oxide resonance seen at $\sim \delta 4.4$ and acetonitrile resonance seen at $\sim \delta 2.1 \mathrm{ppm} \cdot .^{87}$

We propose the model shown in Figure 5 to depict our current understanding of the surface corona of AgNPs produced by F. oxysporum based on our results. We believe that the surface corona is a thin mixed layer comprised predominately of peptides originating from adaptive or protective proteins from MAP kinase cascades triggered by environmental stress (e.g., reactive silver metal ions). To lesser extent, other primary or secondary metabolic peptides may be part of the layer. Peptides are presumed to adsorb stochastically around the silver nanoparticle effectively lowering the surface energy. ${ }^{88-89}$ In terms of 
specific amino acid residues interacting with the AgNP surface, there are reports of proline and hydroxyl-containing residues, along with Cys, Leu, Lys, Arg, Ser, Met, and $\mathrm{NH}_{2}$ groups are known to interact with Ag ions. $\frac{88,90-92}{}$ Collectively, the selection and arrangement of peptides enable nanoparticle stability, establish a reducing environment,,$\underline{88}$ and provide a biological identity. Based on Monopoli and co-workers descriptions of a "hard" and "soft" corona, $\stackrel{14}{ }$ we also believe that such an interface extends to B-AgNPs wherein the mixed corona layer is made up of a "hard" corona with peptides bound to the nanoparticle surface and a "soft" corona that is in equilibrium with the aqueous medium. To this end, we note that other factors such as NP size, shape, surface potential, and biological backgrounds will influence corona formations. Hence, we acknowledge that our assumptions will need to be tested for confirmation. 


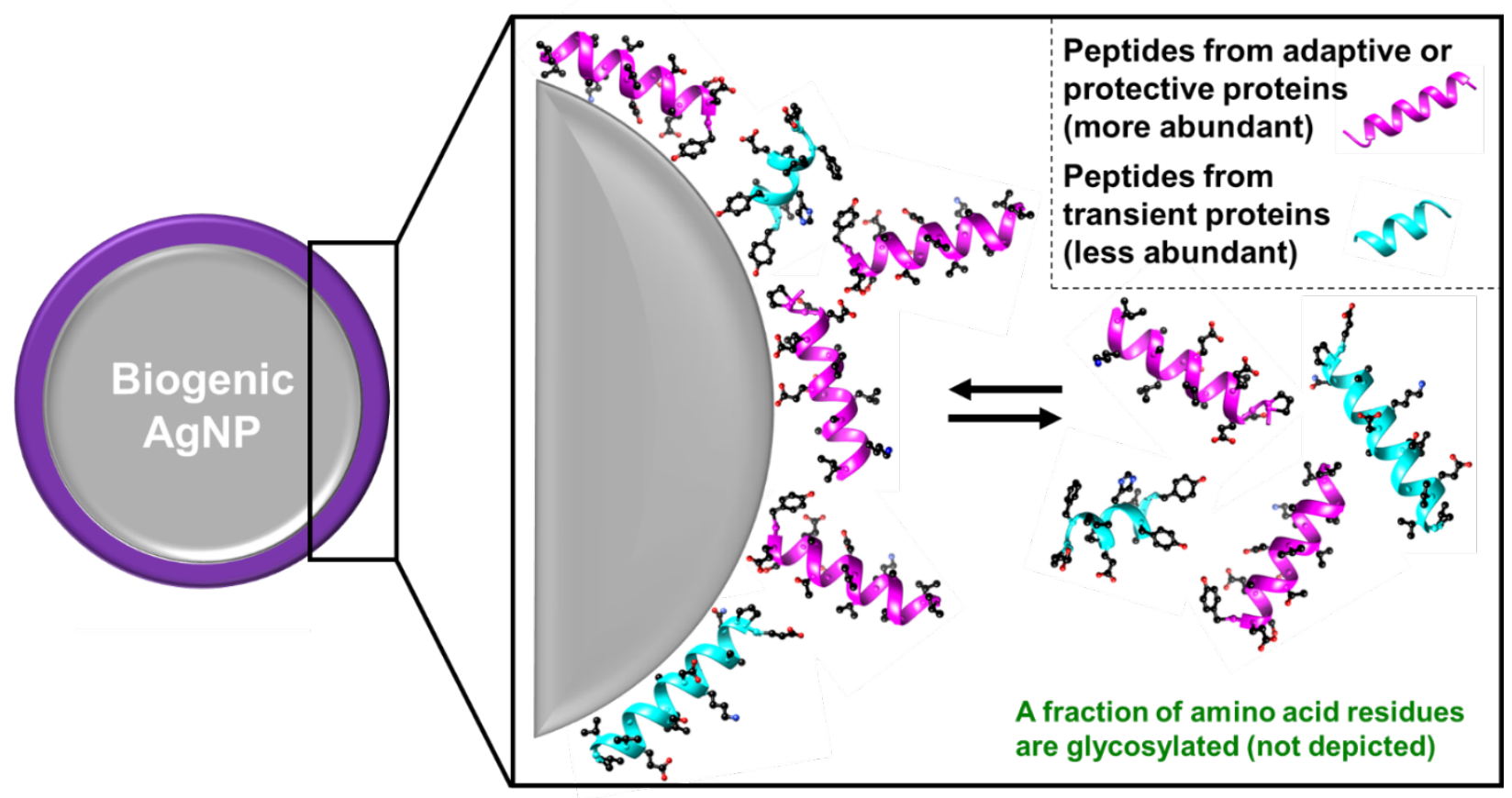

Figure 5. Model of the surface corona of biogenic AgNPs produced by Fusarium oxysporum based on optical and mass spectrometric results. The mixed layer (purple) is predominately comprised of peptides from adaptive or protective proteins (pink) and peptides from transient proteins (blue) synthesized by F. oxysporum in response to environmental stress. A fraction of peptides form a "hard" corona that is bound to the surface and others form a "soft" corona that is in equilibrium with the aqueous medium. Amino acid side chains are shown with black atoms representing carbon, red atoms representing oxygen, and blue atoms representing nitrogen. A fraction of amino acids will be glycosylated, however proportion and $\mathrm{N}$ - or $\mathrm{O}$-linked chemistry is unknown. 


\section{Conclusion}

The surface corona of nanoparticles is the interface with the environment. As such, a detailed understanding of the surface corona is valuable for application development and understanding in vivo interactions. Currently, our understanding the inherent surface corona of biogenic silver nanoparticles is limited. Previous reports investigating biogenic silver nanoparticles have suggested that the surface layer is comprised of capping proteins. However, many of these reports have contributed indirect evidence to substantiate claims and have not clearly addressed excess biomolecules in the dispersion. Currently, there are no reports describing the surface corona of biogenic silver nanoparticles providing both indirect and direct structural and compositional evidence. Using our previously optimized fungal isolate of Fusarium oxysporum, we examination involved both in situ analyses of silver nanoparticle dispersions (indirect) and desorption of the surface corona (direct). Using a series of orthogonal characterization techniques such as UV-visible spectroscopy, TEM, DLS, ZP, SDS-PAGE, MALDI-MS, LC-MS/MS, and NMR; we show evidence the surface corona of biogenic silver nanoparticles produced by Fusarium oxysporum is comprised of a thin mixed layer of peptides and carbohydrates. We hypothesize the origin of these peptides is from adaptive or protective proteins from the mitogen-activated protein kinase cascades triggered by environmental stress (e.g., reactive silver metal ions). Peptides are presumed to adsorb stochastically around the silver nanoparticle to minimize surface energy and may be involved with nanoparticle growth; thus conferring nanoparticle stability, a reducing environment, and biological identity. We believe careful documentation of methods used to characterize the inherent surface corona of biogenic silver 
nanoparticles will allow for more judicious interpretations. Important implications of the surface corona will impact application develop by defining modification strategies with enhanced colloidal stability for nanoparticle-enhanced bioassays and influence in vivo nanoparticle-cell interactions.

\section{Acknowledgements}

SR and MTM acknowledge the strong support of the Mass Spectrometry Facility (University of Alberta, Chemistry), Nuclear Magnetic Resonance Facility (University of Alberta, Chemistry), Biological Services Facility (University of Alberta, Chemistry), and the National Research Council Nanotechnology Research Centre (Edmonton). Special thanks to: Jing Zheng (Mass Spectrometry Facility) who assisted with MALDI-MS and LC-MS/MS experiments and contributed to data analysis; Bela Reiz (University of Alberta) and Professor Liang Li (University of Alberta) also assisted with mass spectrometry experiments and data analysis; Mark Miskolzie (NMR Facility) assisted with NMR experiments and contributed to data analysis; Gareth Lambkin (Biological Services) assisted with SDS-PAGE experiments and data analysis; Hui (Julie) Qian, Kai Cui, and Paul Concepcion (National Research Council NANO) assisted with surface layer TEM experiments. SR and MTM express deep gratitude for the following funding supports: inaugural PhD Accelerator Scholarship (InnoTech Alberta, formerly Alberta Innovates Technology Futures, awarded to SR); National Sciences and Engineering Research Council of Canada (NSERC) Alexander Graham Bell Canada Graduate Scholarship - Doctoral (CGSD3 - 460383 - 2014, awarded to SR); Alberta Innovates Graduate Student Scholarship Top-Up 
Award (awarded to SR); University of Alberta's President's Doctoral Prize of Distinction scholarship (awarded to SR); University of Alberta's Queen Elizabeth II scholarship (awarded to SR); Natural Science and Engineering Research Council of Canada (Discovery Grant to MTM) and Alberta Innovates Nano-programs Grants (AB Innovates G2017000092 McDermo, awarded to MTM). 
7. Table of Contents Graphic

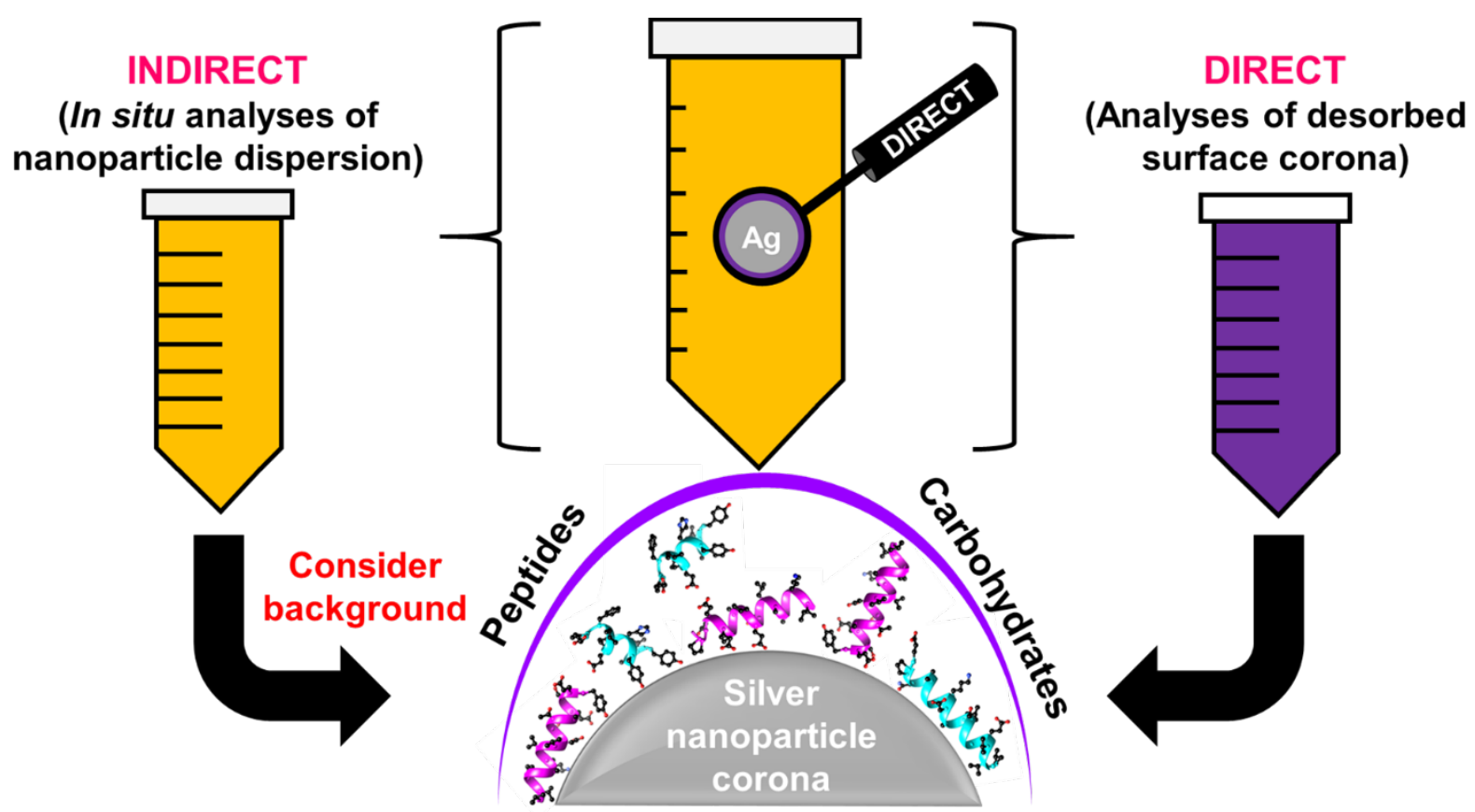




\section{8. $\quad$ References}

1. Turner, A. P. F., Biosensors: sense and sensibility. Chem. Soc. Rev. 2013, 42 (8), 31843196.

2. $\quad$ Stark, W. J.; Stoessel, P. R.; Wohlleben, W.; Hafner, A., Industrial applications of nanoparticles. Chem. Soc. Rev. 2015, 44 (16), 5793-5805.

3. Rai, M.; Ingle, A. P.; Birla, S.; Yadav, A.; Santos, C. A. D., Strategic role of selected noble metal nanoparticles in medicine. Critical Reviews in Microbiology 2016, 42 (5), 696-719.

4. Rajput, S.; Werezuk, R.; Lange, R. M.; McDermott, M. T., Fungal Isolate Optimized for Biogenesis of Silver Nanoparticles with Enhanced Colloidal Stability. Langmuir 2016, 32 (34), 8688-8697.

5. $\quad$ Potara, M.; Bawaskar, M.; Simon, T.; Gaikwad, S.; Licarete, E.; Ingle, A.; Banciu, M.; Vulpoi, A.; Astilean, S.; Rai, M., Biosynthesized silver nanoparticles performing as biogenic SERS-nanotags for investigation of C26 colon carcinoma cells. Colloids and Surfaces B: Biointerfaces 2015, 133, 296-303.

6. Cedervall, T.; Lynch, I.; Lindman, S.; Berggård, T.; Thulin, E.; Nilsson, H.; Dawson, K. A.; Linse, S., Understanding the nanoparticle-protein corona using methods to quantify exchange rates and affinities of proteins for nanoparticles. Proceedings of the National Academy of Sciences 2007, 104 (7), 2050-2055.

7. Monopoli, M. P.; Bombelli, F. B.; Dawson, K. A., Nanobiotechnology: Nanoparticle coronas take shape. Nature Nanotechnology 2011, 6 (1), 11-12.

8. Monopoli, M. P.; Aberg, C.; Salvati, A.; Dawson, K. A., Biomolecular coronas provide the biological identity of nanosized materials. Nat Nanotechnol 2012, 7 (12), 779-86.

9. Cedervall, T.; Lynch, I.; Foy, M.; Berggard, T.; Donnelly, S. C.; Cagney, G.; Linse, S.;

Dawson, K. A., Detailed identification of plasma proteins adsorbed on copolymer nanoparticles. Angew. Chem. Int. Ed. Engl. 2007, 46 (30), 5754-6.

10. Ke, P. C.; Lin, S.; Parak, W. J.; Davis, T. P.; Caruso, F., A Decade of the Protein Corona. ACS Nano 2017.

11. Durán, N.; Silveira, C. P.; Durán, M.; Martinez, D. S. T., Silver nanoparticle protein corona and toxicity: a mini-review. Journal of Nanobiotechnology 2015, 13 (1), 55.

12. Lee, Y. K.; Choi, E.-J.; Webster, T. J.; Kim, S.-H.; Khang, D., Effect of the protein corona on nanoparticles for modulating cytotoxicity and immunotoxicity. International Journal of Nanomedicine 2015, 10, 97-113.

13. Wen, Y.; Geitner, N. K.; Chen, R.; Ding, F.; Chen, P.; Andorfer, R. E.; Govindan, P. N.; Ke, P. C., Binding of cytoskeletal proteins with silver nanoparticles. RSC Advances 2013, 3 (44), 22002-22007.

14. Monopoli, M. P.; Walczyk, D.; Campbell, A.; Elia, G.; Lynch, I.; Baldelli Bombelli, F.; Dawson, K. A., Physical-Chemical Aspects of Protein Corona: Relevance to in Vitro and in Vivo Biological Impacts of Nanoparticles. J. Am. Chem. Soc. 2011, 133 (8), 2525-2534.

15. Vroman, L.; Adams, A.; Fischer, G.; Munoz, P., Interaction of high molecular weight kininogen, factor XII, and fibrinogen in plasma at interfaces. Blood 1980, 55 (1), 156-159.

16. Hirsh, S. L.; McKenzie, D. R.; Nosworthy, N. J.; Denman, J. A.; Sezerman, O. U.; Bilek, M. M. M., The Vroman effect: Competitive protein exchange with dynamic multilayer protein aggregates. Colloids and Surfaces B: Biointerfaces 2013, 103, 395-404. 
17. Monopoli, M. P.; Walczyk, D.; Campbell, A.; Elia, G.; Lynch, I.; Bombelli, F. B.; Dawson, K. A., Physical-chemical aspects of protein corona: relevance to in vitro and in vivo biological impacts of nanoparticles. J. Am. Chem. Soc. 2011, 133.

18. Saha, K.; Rahimi, M.; Yazdani, M.; Kim, S. T.; Moyano, D. F.; Hou, S.; Das, R.; Mout, R.; Rezaee, F.; Mahmoudi, M.; Rotello, V. M., Regulation of Macrophage Recognition through the Interplay of Nanoparticle Surface Functionality and Protein Corona. ACS Nano 2016, 10 (4), 4421-4430.

19. Colangelo, E.; Comenge, J.; Paramelle, D.; Volk, M.; Chen, Q.; Lévy, R., Characterizing Self-Assembled Monolayers on Gold Nanoparticles. Bioconjugate Chem. 2017, 28 (1), 11-22. 20. Duran, N.; Marcato, P. D.; Alves, O. L.; Souza, G. I.; Esposito, E., Mechanistic aspects of biosynthesis of silver nanoparticles by several Fusarium oxysporum strains. $J$ Nanobiotechnology 2005, 3.

21. Sanghi, R.; Verma, P., Biomimetic synthesis and characterisation of protein capped silver nanoparticles. Bioresour. Technol. 2009, 100 (1), 501-504.

22. Mukherjee, P.; Roy, M.; Mandal, B. P.; Dey, G. K.; Mukherjee, P. K.; Ghatak, J.; Tyagi, A. K.; Kale, S. P., Green synthesis of highly stabilized nanocrystalline silver particles by a nonpathogenic and agriculturally important fungus T. asperellum. Nanotechnology 2008, 19 (7), 075103.

23. Birla, S. S.; Gaikwad, S. C.; Gade, A. K.; Rai, M. K., Rapid Synthesis of Silver Nanoparticles from Fusarium oxysporum by Optimizing Physicocultural Conditions. The Scientific World Journal 2013, 2013, 12.

24. Mukherjee, P.; Senapati, S.; Mandal, D.; Ahmad, A.; Khan, M.; Kumar, R.; Sastry, M., Extracellular synthesis of gold nanoparticles by the fungus Fusarium oxysporum. ChemBioChem 2002, 3, 461 - 463.

25. Ahmad, A.; Mukherjee, P.; Senapati, S.; Mandal, D.; Khan, M. I.; Kumar, R.; Sastry, M., Extracellular biosynthesis of silver nanoparticles using the fungus Fusarium oxysporum. Colloids and Surfaces B: Biointerfaces 2003, 28 (4), 313-318.

26. Duran, N.; Marcato, P. D.; De Souza, G. I. H.; Alves, O. L.; Esposito, E., Antibacterial Effect of Silver Nanoparticles Produced by Fungal Process on Textile Fabrics and Their Effluent Treatment. JOURNAL OF BIOMEDICAL NANOTECHNOLOGY 2007, 3 (2), 203-208.

27. Bansal, V.; Rautaray, D.; Ahmad, A.; Sastry, M., Biosynthesis of zirconia nanoparticles using the fungus Fusarium oxysporum. J. Mater. Chem. 2004, 14 (22), 3303-3305.

28. Jain, N.; Bhargava, A.; Majumdar, S.; Tarafdar, J. C.; Panwar, J., Extracellular biosynthesis and characterization of silver nanoparticles using Aspergillus flavus NJP08: A mechanism perspective. Nanoscale 2011, 3 (2), 635-641.

29. Marcato, P. D.; Nakasato, G.; Brocchi, M.; Melo, P. S.; Huber, S. C.; Ferreira, I. R.; Alves, O. L.; Duran, N., Biogenic silver nanoparticles: Antibacterial and cytotoxicity applied to textile fabrics. 2012, 20, 69-76.

30. Qian, H.; Laurentius, L.; Egerton, R. F., Artefacts Induced on Soft Layer of Hybrid Metallic Nanoparticles in TEM. Microsc. Microanal. 2015, 21 (S3), 1551-1552.

31. Green, M. R., Molecular cloning : a laboratory manual. 4th ed. ed.; Sambrook, J., Ed. Cold Spring Harbor Laboratory Press: Cold Spring Harbor, N.Y. :, 2012.

32. Bollag, D. M.; Edelstein, S. J., Protein methods / Daniel M. Bollag, Stuart J. Edelstein. New York : Wiley-Liss, c1991.: 1991.

33. Schagger, H., Tricine-SDS-PAGE. Nat. Protocols 2006, 1 (1), 16-22. 
34. Neuhoff, V.; Arold, N.; Taube, D.; Ehrhardt, W., Improved staining of proteins in polyacrylamide gels including isoelectric focusing gels with clear background at nanogram sensitivity using Coomassie Brilliant Blue G-250 and R-250. Electrophoresis 1988, 9 (6), 255-262.

35. Shevchenko, A.; Wilm, M.; Vorm, O.; Mann, M., Mass Spectrometric Sequencing of Proteins from Silver-Stained Polyacrylamide Gels. Anal. Chem. 1996, 68 (5), 850-858.

36. Perkins, D. N.; Pappin, D. J. C.; Creasy, D. M.; Cottrell, J. S., Probability-based protein identification by searching sequence databases using mass spectrometry data.

Electrophoresis 1999, 20 (18), 3551-3567.

37. http://www.matrixscience.com/help/scoring help.html

38. Hwang, T. L.; Shaka, A. J., Water Suppression That Works. Excitation Sculpting Using Arbitrary Wave-Forms and Pulsed-Field Gradients. Journal of Magnetic Resonance, Series A 1995, 112 (2), 275-279.

39. Dalvit, C., Efficient multiple-solvent suppression for the study of the interactions of organic solvents with biomolecules. J. Biomol. NMR 1998, 11 (4), 437-444.

40. Harris, R. B. B., E.D.; Cabral De Menezes, S.M.; Goodfellow, R.; and Granger, P., NMR Nomenclature. Nuclear Spin Properties and Conventions for Chemical Shifts. IUPAC Recommendations 2001. . Pure Appl. Chem. 2001, 73 (11), 1795-1818.

41. Mabuchi, M.; Takenaka, T.; Fujiyoshi, Y.; Uyeda, N., Surface enhanced Raman scattering of citrate ions adsorbed on gold sol particles. Surf. Sci. 1982, 119 (2-3), 150-158.

42. Weisbecker, C. S.; Merritt, M. V.; Whitesides, G. M., Molecular Self-Assembly of Aliphatic Thiols on Gold Colloids. Langmuir 1996, 12 (16), 3763-3772.

43. Laurentius, L. B. Modification and Application of Gold Nanoparticles in SurfaceBased Immunoassays. Thesis, University of Alberta, 2012.

44. Fernandez-Iglesias, N.; Bettmer, J., Complementary mass spectrometric techniques for the quantification of the protein corona: a case study on gold nanoparticles and human serum proteins. Nanoscale 2015, 7 (34), 14324-14331.

45. Mie, G., [Beiträge zur Optik trüber Medien, speziell kolloidaler Metallösungen] Contributions to the optics of turbid media, particularly of colloidal metal solutions. Annalen der Physik 1908, 330 (3), 377-445.

46. Horvath, H., Gustav Mie and the scattering and absorption of light by particles: Historic developments and basics. J. Quant. Spectrosc. Radiat. Transfer 2009, 110 (11), 787799.

47. Jain, N.; Bhargava, A.; Rathi, M.; Dilip, R. V.; Panwar, J., Removal of Protein Capping Enhances the Antibacterial Efficiency of Biosynthesized Silver Nanoparticles. PLOS ONE 2015, 10 (7), e0134337.

48. Rasband, W. S. ImageJ, U. S. National Institutes of Health, Bethesda, MD. http://imagej.nih.gov/ij/.

49. Weber, K.; Osborn, M., The Reliability of Molecular Weight Determinations by Dodecyl Sulfate-Polyacrylamide Gel Electrophoresis. J. Biol. Chem. 1969, 244 (16), 44064412.

50. Zhang, X.; He, X.; Wang, K.; Yang, X., Different Active Biomolecules Involved in Biosynthesis of Gold Nanoparticles by Three Fungus Species. Journal of Biomedical Nanotechnology 2011, 7 (2), 245-254. 
51. Biosciences, B. D., BD Bionutrients Technical Manual In Advanced Bioprocessing [Online] Fourth ed.; Becton Dickinson and Company: Sparks, MD, 2015.

https://www.bd.com/ds/technicalCenter/misc/lcn01558-bionutrients-manual.pdf.

52. Anil Kumar, S.; Abyaneh, M. K.; Gosavi, S. W.; Kulkarni, S. K.; Pasricha, R.; Ahmad, A.; Khan, M. I., Nitrate reductase-mediated synthesis of silver nanoparticles from AgNO3. Biotechnol. Lett 2007, 29 (3), 439-445.

53. Gessler, N. N.; Aver'yanov, A. A.; Belozerskaya, T. A., Reactive oxygen species in regulation of fungal development. Biochemistry (Moscow) 2007, 72 (10), 1091-1109.

54. Sun, Y.; Yi, X.; Peng, M.; Zeng, H.; Wang, D.; Li, B.; Tong, Z.; Chang, L.; Jin, X.; Wang, X., Proteomics of Fusarium oxysporum Race 1 and Race 4 Reveals Enzymes Involved in Carbohydrate Metabolism and Ion Transport That Might Play Important Roles in Banana Fusarium Wilt. PLOS ONE 2014, 9 (12), e113818.

55. Aguirre, J.; Hansberg, W.; Navarro, R., Fungal responses to reactive oxygen species. Medical Mycology 2006, 44 (Supplement_1), S101-S107.

56. Sharma, P.; Jha, A. B.; Dubey, R. S.; Pessarakli, M., Reactive Oxygen Species, Oxidative Damage, and Antioxidative Defense Mechanism in Plants under Stressful Conditions. Journal of Botany 2012, 2012, 26.

57. Gough, D. R.; Cotter, T. G., Hydrogen peroxide: a Jekyll and Hyde signalling molecule. Cell Death and Dis 2011, 2, e213.

58. Lamb, C.; Dixon, R. A., THE OXIDATIVE BURST IN PLANT DISEASE RESISTANCE. Annual Review of Plant Physiology and Plant Molecular Biology 1997, 48 (1), 251-275.

59. Hamel, L.-P.; Nicole, M.-C.; Duplessis, S.; Ellis, B. E., Mitogen-Activated Protein Kinase Signaling in Plant-Interacting Fungi: Distinct Messages from Conserved Messengers. The Plant Cell 2012, 24 (4), 1327-1351.

60. Gavanji, S.; Abdul Aziz, H.; Larki, B.; Mojiri, A., Bioinformatics prediction of interaction of silver nitrate and nano silver on catalase and nitrat reductase. International Journal of Scientific Research in Environmental Sciences 2013, 1 (2), 26-35.

61. Ding, Z.; Li, M.; Sun, F.; Xi, P.; Sun, L.; Zhang, L.; Jiang, Z., Mitogen-Activated Protein Kinases Are Associated with the Regulation of Physiological Traits and Virulence in Fusarium oxysporum f. sp. cubense. PLoS ONE 2015, 10 (4), e0122634.

62. Xu, J.-R., MAP Kinases in Fungal Pathogens. Fungal Genetics and Biology 2000, 31 (3), 137-152.

63. Bailey, B. A.; Jennings, J. C.; Anderson, J. D., The 24-kDa protein from Fusarium oxysporum f.sp. erythroxyli: occurrence in related fungi and the effect of growth medium on its production. Can. J. Microbiol. 1997, 43 (1), 45-55.

64. Radici, L.; Bianchi, M.; Crinelli, R.; Magnani, M., Ubiquitin C gene: Structure, function, and transcriptional regulation. Advances in Bioscience and Biotechnology 2013, 4, 10571062.

65. Hershko, A.; Ciechanover, A., THE UBIQUITIN SYSTEM. Annu. Rev. Biochem 1998, 67 (1), 425-479.

66. Goldstein, G.; Scheid, M.; Hammerling, U.; Schlesinger, D. H.; Niall, H. D.; Boyse, E. A., Isolation of a polypeptide that has lymphocyte-differentiating properties and is probably represented universally in living cells. Proceedings of the National Academy of Sciences 1975, 72 (1), 11-15. 
67. Calzolai, L.; Franchini, F.; Gilliland, D.; Rossi, F., Protein-Nanoparticle Interaction: Identification of the Ubiquitin-Gold Nanoparticle Interaction Site. Nano Lett. 2010, 10 (8), 3101-3105.

68. Jha, A. K.; Prasad, K.; Prasad, K.; Kulkarni, A. R., Plant system: Nature's nanofactory. Colloids and Surfaces B: Biointerfaces 2009, 73 (2), 219-223.

69. Segorbe, D.; Di Pietro, A.; Pérez-Nadales, E.; Turrà, D., Three Fusarium oxysporum mitogen-activated protein kinases (MAPKs) have distinct and complementary roles in stress adaptation and cross-kingdom pathogenicity. Molecular Plant Pathology 2016, n/a$\mathrm{n} / \mathrm{a}$.

70. Gustin, M. C.; Albertyn, J.; Alexander, M.; Davenport, K., MAP Kinase Pathways in the Yeast Saccharomyces cerevisiae. Microbiology and Molecular Biology Reviews 1998, 62 (4), 1264-1300.

71. Pitzschke, A.; Schikora, A.; Hirt, H., MAPK cascade signalling networks in plant defence. Current Opinion in Plant Biology 2009, 12 (4), 421-426.

72. Schaeffer, H. J.; Weber, M. J., Mitogen-Activated Protein Kinases: Specific Messages from Ubiquitous Messengers. Molecular and Cellular Biology 1999, 19 (4), 2435-2444. 73. Li, M.; Liu, J.; Zhang, C., Evolutionary History of the Vertebrate Mitogen Activated Protein Kinases Family. PLoS ONE 2011, 6 (10), e26999.

74. Segorbe, D.; Di Pietro, A.; Perez-Nadales, E.; Turra, D., Three Fusarium oxysporum mitogen-activated protein kinases (MAPKs) have distinct and complementary roles in stress adaptation and cross-kingdom pathogenicity. Mol Plant Pathol 2017, 18 (7), 912-924. 75. $\quad$ Kracht, S.; Messerer, M.; Lang, M.; Eckhardt, S.; Lauz, M.; Grobéty, B.; Fromm, K. M.; Giese, B., Electron Transfer in Peptides: On the Formation of Silver Nanoparticles. Angew. Chem. Int. Ed. 2015, 54 (10), 2912-2916.

76. Ballottin, D.; Fulaz, S.; Souza, M. L.; Corio, P.; Rodrigues, A. G.; Souza, A. O.; Gaspari, P. M.; Gomes, A. F.; Gozzo, F.; Tasic, L., Elucidating Protein Involvement in the Stabilization of the Biogenic Silver Nanoparticles. Nanoscale Research Letters 2016, 11 (1), 1-9.

77. Swiss Prot Database. 5933 active entries. Accessed 15 March 2017.

78. Swiss Prot Database. 5933 active entries. Accessed 15 March 2017.

79. Swiss Prot Database. 5933 active entries. Accessed 15 March 2017.

80. Wan, S.; Kelly, P. M.; Mahon, E.; Stöckmann, H.; Rudd, P. M.; Caruso, F.; Dawson, K. A.; Yan, Y.; Monopoli, M. P., The "Sweet" Side of the Protein Corona: Effects of Glycosylation on Nanoparticle-Cell Interactions. ACS Nano 2015, 9 (2), 2157-2166.

81. Bubb, W. A., NMR spectroscopy in the study of carbohydrates: Characterizing the structural complexity. Concepts in Magnetic Resonance Part A 2003, 19A (1), 1-19.

82. Wüthrich, K., NMR of proteins and nucleic acids. Wiley: New York :, 1986.

83. Masjedi-Arani, M.; Salavati-Niasari, M., Effect of carbohydrate sugars as a capping agent on the size and morphology of pure $\mathrm{Zn} 2 \mathrm{SnO} 4$ nanostructures and their optical properties. Mater. Lett. 2016, 174, 71-74.

84. de la Fuente, J. M.; Penadés, S., Glyconanoparticles: Types, synthesis and applications in glycoscience, biomedicine and material science. Biochimica et Biophysica Acta (BBA) -

General Subjects 2006, 1760 (4), 636-651.

85. Suvarna, S.; Das, U.; Kc, S.; Mishra, S.; Sudarshan, M.; Saha, K. D.; Dey, S.; Chakraborty, A.; Narayana, Y., Synthesis of a novel glucose capped gold nanoparticle as a better theranostic candidate. PLOS ONE 2017, 12 (6), e0178202. 
86. Alocilja, E. C.; Anderson, M. J.; Torres-Chavolla, E. Metallic Nanoparticle Synthesis with Carbohydrate Capping Agent. Feb. 28, 20172017.

87. Fulmer, G. R.; Miller, A. J. M.; Sherden, N. H.; Gottlieb, H. E.; Nudelman, A.; Stoltz, B. M.; Bercaw, J. E.; Goldberg, K. I., NMR Chemical Shifts of Trace Impurities: Common Laboratory Solvents, Organics, and Gases in Deuterated Solvents Relevant to the Organometallic Chemist. Organometallics 2010, 29 (9), 2176-2179.

88. $\quad$ Naik, R. R.; Stringer, S. J.; Agarwal, G.; Jones, S. E.; Stone, M. O., Biomimetic synthesis and patterning of silver nanoparticles. Nat Mater 2002, 1 (3), 169-172.

89. Kelly, P. M.; Åberg, C.; Polo, E.; O'Connell, A.; Cookman, J.; Fallon, J.; KrpetićŽeljka; Dawson, K. A., Mapping protein binding sites on the biomolecular corona of nanoparticles. Nat Nano 2015, 10 (5), 472-479.

90. Clem Gruen, L., Interaction of amino acids with silver(I) ions. Biochimica et Biophysica Acta (BBA) - Protein Structure 1975, 386 (1), 270-274.

91. Alarcon, E. I.; Bueno-Alejo, C. J.; Noel, C. W.; Stamplecoskie, K. G.; Pacioni, N. L.; Poblete, H.; Scaiano, J. C., Human serum albumin as protecting agent of silver nanoparticles: role of the protein conformation and amine groups in the nanoparticle stabilization. J. Nanopart. Res. 2013, 15 (1), 1-14.

92. Poblete, H.; Agarwal, A.; Thomas, S. S.; Bohne, C.; Ravichandran, R.; Phospase, J.; Comer, J.; Alarcon, E. I., New Insights into Peptide-Silver Nanoparticle Interaction: Deciphering the Role of Cysteine and Lysine in the Peptide Sequence. Langmuir 2016, 32 (1), 265-73. 
Illuminating the surface corona of biogenic silver nanoparti... (2.68 MiB) view on ChemRxiv • download file 


\section{Supporting Information}

\section{Illuminating the surface corona of biogenic silver nanoparticles}

\section{Sunil Rajput, ${ }^{\mathrm{a}, \mathrm{b}}$ and Mark T. McDermott ${ }^{\mathrm{a} \dagger}$}

${ }^{a}$ University of Alberta, Department of Chemistry, Edmonton, Alberta, Canada T6G 2G2

${ }^{b}$ InnoTech Alberta, Ecosystems and Plant Sciences, PO Bag 4000, Vegreville, Alberta, Canada T9C $1 \mathrm{~T} 4$

${ }^{\dagger}$ Corresponding author

Contact information:

Dr. Mark T. McDermott

Department of Chemistry

11227 Saskatchewan Drive

University of Alberta T6G 2G2

Canada

780-492-3687

mmcdermo@ualberta.ca 

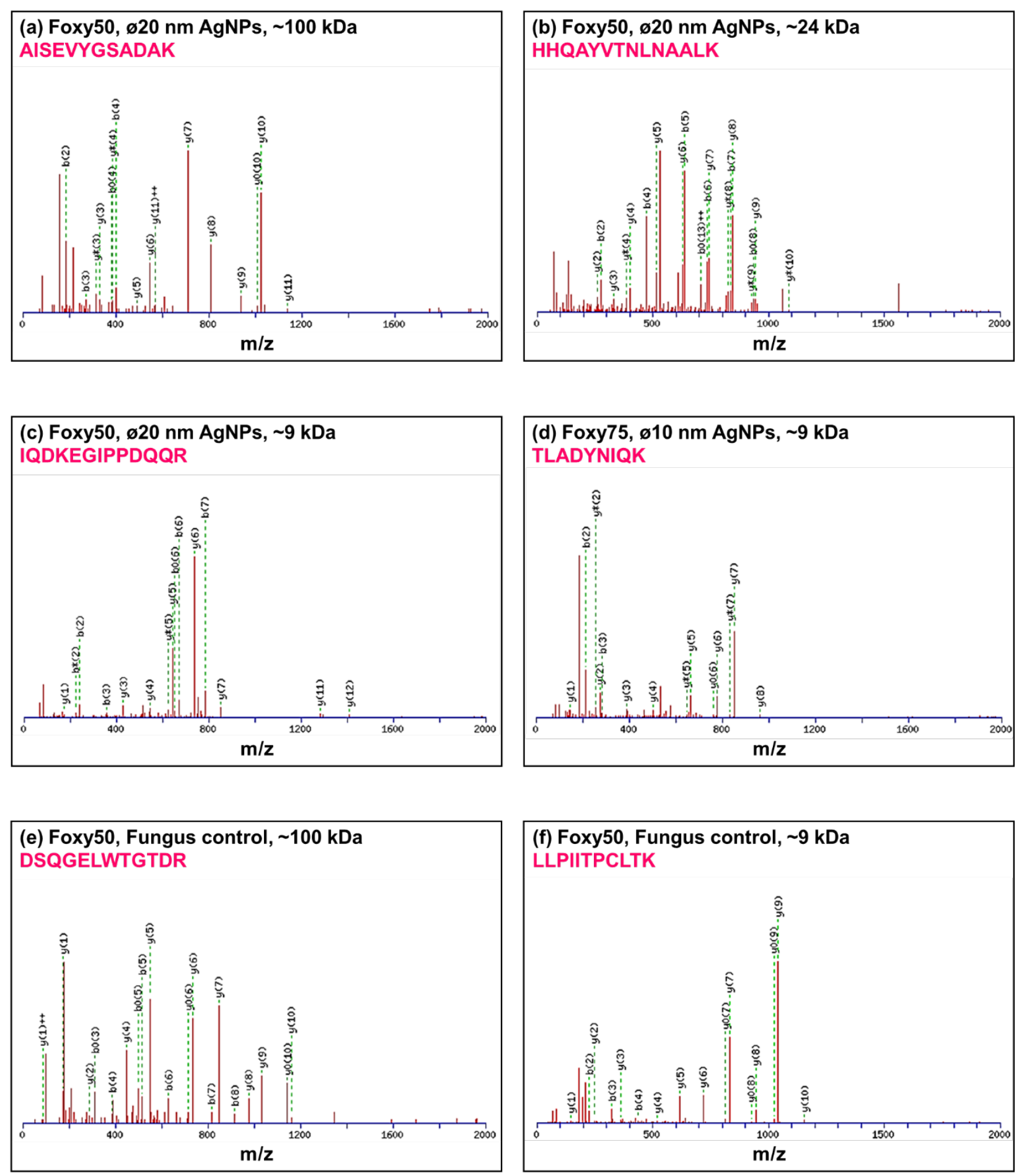

Figure S1. Tandem mass spectra of highest peptide scores for gel extracted bands. Plots of intensity as a function of mass to charge $(\mathrm{m} / \mathrm{z})$ ratio. (a-c) Fusarium oxysporum exposed to $1 \mathrm{mM} \mathrm{AgNO}_{3}$ at $50^{\circ} \mathrm{C}$ resulting in $\sim \varnothing 20 \mathrm{~nm}$ silver nanoparticles. (d) Fusarium oxysporum exposed to $1 \mathrm{mM} \mathrm{AgNO}_{3}$ at $75^{\circ} \mathrm{C}$ resulting in $\sim \varnothing 10 \mathrm{~nm}$ silver nanoparticles. (e-f) Control fungal filtrate at $50^{\circ} \mathrm{C}$ without exposure to $1 \mathrm{mM} \mathrm{AgNO}_{3}$. 


\section{Optimization of surface corona desorption using acetonitrile}

We tracked the effectiveness of acetonitrile in desorbing the surface corona by extinction spectroscopy and DLS. Figure S2 contains an extinction plot showing $\sim ø 20 \mathrm{~nm}$ AgNPs with a single extinction band with a surface plasmon peak centred at $402 \mathrm{~nm}$. After these NPs were treated with $40 \%$ acetonitrile, centrifuged, and resuspended in $\mathrm{DI} \mathrm{H}_{2} \mathrm{O}$, the AgNPs destabilized as evidenced by the loss in the extinction band in Figure S2. We also used extinction spectroscopy to estimate the total protein at each step for an approximate protein recovery by recording the absorbance at $260 \mathrm{~nm}$ and $280 \mathrm{~nm}$. Tables S1 and S2 contain our estimated protein concentrations for both $\sim \varnothing 20 \mathrm{~nm}$ and $\sim ø 10 \mathrm{~nm}$ treated with either $40 \%$ acetonitrile (more polar) or $80 \%$ acetonitrile (less polar), respectively.

Consistent with our previous work, $\stackrel{4}{2}$ ø10 nm AgNPs have a higher abundance of proteins compared to $\sim ø 20 \mathrm{~nm}$ AgNPs. In all cases, most proteins are removed $(\sim 80-$ $94 \%$ ) in the supernatant after centrifugation (Tables S1 and S2). It is important to note that in situ characterization of capping proteins would contain more abundance of these proteins, resulting in higher levels of excess or background protein. For ø20 nm AgNPs, $2-7 \%$ of proteins are recovered within the acetonitrile fractions with more recovered using $40 \%$ rather than $80 \%$ (Tables S1 and S2). For ø10 nm AgNPs, 5-15\% of proteins are recovered in the acetonitrile fractions with a more pronounced improvement using $40 \%$ acetonitrile (Tables S1 and S2). The residual protein fraction recovered after the removal of the surface corona and resuspension in $\mathrm{DI}_{2} \mathrm{O}$ is $<5 \%$, except for $\sim ø 10 \mathrm{~nm}$ treated with $80 \%$ acetonitrile (Tables S1 and S2). Though most protein fraction can be displaced with a single wash step, a small fraction of proteins will likely remain chemically bonded to the 
nanoparticle surface (e.g., cysteine or amine linkages). Based on our estimated protein analyses, we selected $40 \%$ acetonitrile to be our choice for desorbing the surface corona. To track destabilization of the AgNPs after removal of the surface corona, we used DLS to monitor the change in hydrodynamic diameter. We expect that the AgNPs will destabilize (aggregate) by removing the surface corona. Table S3 contains our results confirming an increase in hydrodynamic diameter with acetonitrile treatments. For $\sim ø 20 \mathrm{~nm}$ AgNPs, the hydrodynamic diameter increases from $57 \pm 1 \mathrm{~nm}$ to $687 \pm 351 \mathrm{~nm}$ after two treatments of $40 \%$ acetonitrile. We also tried $80 \%$ acetonitrile and a similar, yet less pronounced increase in hydrodynamic diameter is recorded for $\sim ø 20 \mathrm{~nm}$ AgNPs. Our results for $\sim ø 20$ nm AgNPs were consistent with our $\sim ø 10 \mathrm{~nm}$ AgNPs. Thus, our DLS study confirms that the NPs destabilize (aggregate) with the removal of the surface corona and $40 \%$ acetonitrile was more efficient than $80 \%$ in desorbing the surface corona. Thus, we proceeded to determine the surface corona composition of B-AgNPs by removal of excess free proteins, $40 \%$ treatment of the AgNPs, followed by mass spectrometry and nuclear magnetic resonance. 


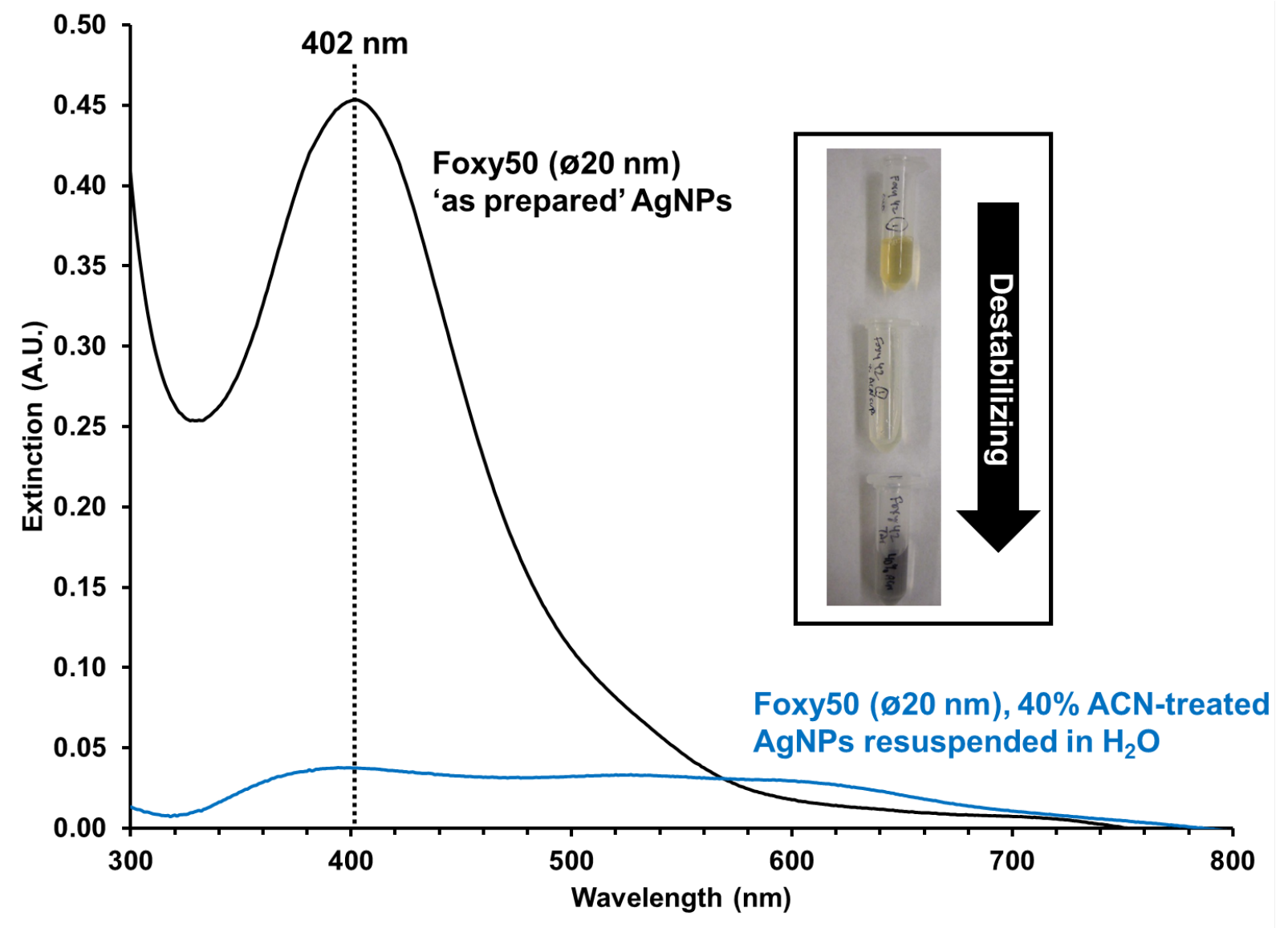


Figure S2. Extinction plot of $\sim \varnothing 20 \mathrm{~nm}$ silver nanoparticles produced by Fusarium oxysporum (Foxy50) with and without acetonitrile treatment to desorb the surface corona. The black spectra shows the extinction band of 'as prepared' nanoparticles with a surface plasmon peak at $402 \mathrm{~nm}$. The blue spectra shows the extinction of the $\sim \varnothing 20 \mathrm{~nm}$ treated with $40 \%$ acetonitrile, centrifuged, and resuspended in deionized water. Inset shows the 'as prepared' nanoparticles with characteristic yellow colour indicting of plasmonic AgNPs (top), the middle tube is the acetonitrile supernatant removed after centrifugation, the bottom tube show AgNPs resuspended in water after acetonitrile treatment. Grayish coloured solution is characteristic of destabilized (aggregated) nanoparticles, suggesting removal of the surface corona.

Table S1. Protein concentration of biogenic silver nanoparticles in situ and desorbing of the surface layer using $40 \%$ acetonitrile.

\begin{tabular}{|c|c|c|c|}
\hline $\begin{array}{c}\text { Biogenic } \\
\text { nanoparticle } \\
\text { diameter }\end{array}$ & Sample description & $\begin{array}{l}\text { Total protein }^{\mathrm{a}} \\
(\mathrm{mcg} / \mathrm{mL})\end{array}$ & $\begin{array}{l}\text { Normalized percent } \\
\text { recovery }{ }^{\mathbf{b}}\end{array}$ \\
\hline \multirow[t]{4}{*}{$\sim \varnothing 20 \mathrm{~nm}$} & $\begin{array}{l}\text { 'As prepared' AgNP } \\
\text { dispersion' }\end{array}$ & $1439 \pm 23$ & $100 \%$ \\
\hline & Supernatant fraction & $1279 \pm 10$ & $87-91 \%$ \\
\hline & $\begin{array}{l}\text { Supernatant from } 40 \% \\
\text { acetonitrile treated } \\
\text { AgNPs }\end{array}$ & $73 \pm 7$ & $5-7 \%$ \\
\hline & $\begin{array}{l}40 \% \text { acetonitrile } \\
\text { treated AgNPs pellet } \\
\text { and resuspended in } \\
\left.\text { water ( } 2^{\text {nd }} \text { treatment }\right)^{d}\end{array}$ & $29 \pm 19$ & $1-3 \%$ \\
\hline \multirow[t]{2}{*}{$\sim \varnothing 10 \mathrm{~nm}$} & $\begin{array}{l}\text { 'As prepared' AgNP } \\
\text { dispersionc }\end{array}$ & $1883 \pm 11$ & $100 \%$ \\
\hline & Supernatant fraction & $1537 \pm 36$ & $80-83 \%$ \\
\hline
\end{tabular}




\section{Supernatant from $40 \%$}

\begin{tabular}{|c|c|c|}
\hline $\begin{array}{l}\text { acetonitrile treated } \\
\text { AgNPs }\end{array}$ & $251 \pm 25$ & $12-15 \%$ \\
\hline $\begin{array}{l}40 \% \text { acetonitrile } \\
\text { treated AgNPs pellet } \\
\text { and resuspended in } \\
{\text { water }\left(2^{\text {nd }} \text { treatment) }\right.}^{\text {d }}\end{array}$ & $45 \pm 36$ & $1-4 \%$ \\
\hline
\end{tabular}

${ }^{\text {a }}$ Estimated protein concentration was calculated according to [Protein] $\mathrm{mg} / \mathrm{mL}=1.55^{*} \mathrm{~A}_{280^{-}}$ $0.76 * \mathrm{~A}_{260}{ }^{1-2}$ Values reported in micrograms/millilitre. Error is reported as standard deviation of three measurements.

${ }^{\text {b }}$ Normalized to 'as-prepared' sample. Reported values are approximations.

${ }^{\mathrm{c}}$ Silver nanoparticles dispersed in aqueous medium recovered post separation from fungal culture (i.e. post filtration).

${ }^{\mathrm{d}}$ AgNPs treated with $40 \%$ acetonitrile, centrifuged, and resuspended in water ( $2^{\text {nd }}$ treatment).

Table S2. Protein concentration of biogenic silver nanoparticles in situ and desorbing of the surface layer using $80 \%$ acetonitrile.

\begin{tabular}{|c|c|c|c|}
\hline $\begin{array}{c}\text { Biogenic } \\
\text { nanoparticle } \\
\text { diameter }\end{array}$ & Sample description & $\begin{array}{l}\text { Total protein }^{a} \\
(\mathrm{mcg} / \mathrm{mL})\end{array}$ & $\begin{array}{c}\text { Normalized } \\
\text { percent recovery }\end{array}$ \\
\hline \multirow[t]{4}{*}{ Ø20 nm } & $\begin{array}{l}\text { 'As prepared' AgNP } \\
\text { dispersion' }\end{array}$ & $1439 \pm 23$ & $100 \%$ \\
\hline & Supernatant fraction & $1352 \pm 106$ & $85-94 \%$ \\
\hline & $\begin{array}{l}\text { Supernatant from 80\% } \\
\text { acetonitrile treated } \\
\text { AgNPs }\end{array}$ & $47 \pm 19$ & $2-4 \%$ \\
\hline & $\begin{array}{l}80 \% \text { acetonitrile } \\
\text { treated AgNPs pellet } \\
\text { and resuspended in } \\
\left.\text { water ( } 2^{\text {nd }} \text { treatment }\right)^{\mathrm{d}}\end{array}$ & $16 \pm 3$ & $1-3 \%$ \\
\hline \multirow[t]{3}{*}{$\sim \varnothing 10 \mathrm{~nm}$} & $\begin{array}{l}\text { 'As prepared' AgNP } \\
\text { dispersion' }\end{array}$ & $1883 \pm 11$ & $100 \%$ \\
\hline & Supernatant fraction & $1543 \pm 33$ & $81-83 \%$ \\
\hline & $\begin{array}{l}\text { Supernatant from } 80 \% \\
\text { acetonitrile treated }\end{array}$ & $111 \pm 5$ & $5-6 \%$ \\
\hline
\end{tabular}




\section{AgNPs}

$80 \%$ acetonitrile

treated AgNPs pellet

and resuspended in

$120 \pm 63$

$3-10 \%$

water $\left(2^{\text {nd }} \text { treatment }\right)^{\mathrm{d}}$

\footnotetext{
${ }^{\mathrm{a}}$ Estimated protein concentration was calculated according to [Protein] $\mathrm{mg} / \mathrm{mL}=1.55^{*} \mathrm{~A}_{280^{-}}$ $0.76 * \mathrm{~A}_{260}{ }^{1-2}$ Values reported in micrograms/millilitre. Error is reported as standard deviation of three measurements.

${ }^{\mathrm{b}}$ Normalized to 'as-prepared' sample. Reported values are approximations.

${ }^{\mathrm{c}}$ Silver nanoparticles dispersed in aqueous medium recovered post separation from fungal culture (i.e. post filtration).

${ }^{\mathrm{d}}$ AgNPs treated with $80 \%$ acetonitrile, centrifuged, and resuspended in water ( $2{ }^{\text {nd }}$ treatment).
}

Table S3. Tracking changes in hydrodynamic diameter of biogenic silver nanoparticles in situ and desorbing of the surface layer using either $40 \%$ or $80 \%$ acetonitrile.

\begin{tabular}{|c|c|c|}
\hline $\begin{array}{c}\text { Biogenic } \\
\text { nanoparticle } \\
\text { diameter }\end{array}$ & Sample description & $\begin{array}{l}\text { Hydrodynamic diameter } \\
\text { (nm) }\end{array}$ \\
\hline \multirow[t]{4}{*}{$\sim \varnothing 20 \mathrm{~nm}$} & 'As prepared' AgNP dispersion ${ }^{\mathrm{b}}$ & $57 \pm 1$ \\
\hline & $\begin{array}{l}40 \% \text { acetonitrile treated AgNPs pellet } \\
\text { and resuspended in water (1st } \\
\text { treatment) } \\
40 \% \text { acetonitrile treated AgNPs pellet } \\
\text { and resuspended in water ( } 2 \text { nd } \\
\text { treatment) }^{c}\end{array}$ & $687 \pm 351$ \\
\hline & $\begin{array}{l}80 \% \text { acetonitrile treated AgNPs pellet } \\
\text { and resuspended in water (1st } \\
\text { treatment) }^{\mathrm{c}}\end{array}$ & $126 \pm 1$ \\
\hline & $\begin{array}{l}80 \% \text { acetonitrile treated AgNPs pellet } \\
\text { and resuspended in water ( } 2 \text { nd } \\
\text { treatment) }^{c}\end{array}$ & $371 \pm 15$ \\
\hline \multirow[t]{2}{*}{$\sim \varnothing 10 \mathrm{~nm}$} & 'As prepared' AgNP dispersion ${ }^{b}$ & $22 \pm 1$ \\
\hline & $\begin{array}{l}40 \% \text { acetonitrile treated AgNPs pellet } \\
\text { and resuspended in water (1st } \\
\text { treatment) }^{c}\end{array}$ & $64 \pm 1$ \\
\hline
\end{tabular}


$40 \%$ acetonitrile treated AgNPs pellet

\begin{tabular}{|c|c|}
\hline $\begin{array}{l}\text { and resuspended in water (2nd } \\
\text { treatment) }^{c}\end{array}$ & $779 \pm 56$ \\
\hline $\begin{array}{l}80 \% \text { acetonitrile treated AgNPs pellet } \\
\text { and resuspended in water (1st } \\
\text { treatment) }^{c}\end{array}$ & $82 \pm 2$ \\
\hline $\begin{array}{l}80 \% \text { acetonitrile treated AgNPs pellet } \\
\text { and resuspended in water ( } 2 \text { nd } \\
\text { treatment) }^{c}\end{array}$ & $319 \pm 12$ \\
\hline
\end{tabular}

${ }^{\mathrm{a}}$ Z-Average based on intensity. Error is reported as standard deviation of three measurements.

${ }^{\mathrm{b}}$ Silver nanoparticles dispersed in aqueous medium recovered post separation from fungal culture (i.e. post filtration).

${ }^{\mathrm{c}}$ Silver nanoparticles treated with acetonitrile, centrifuged, and resuspended in water.

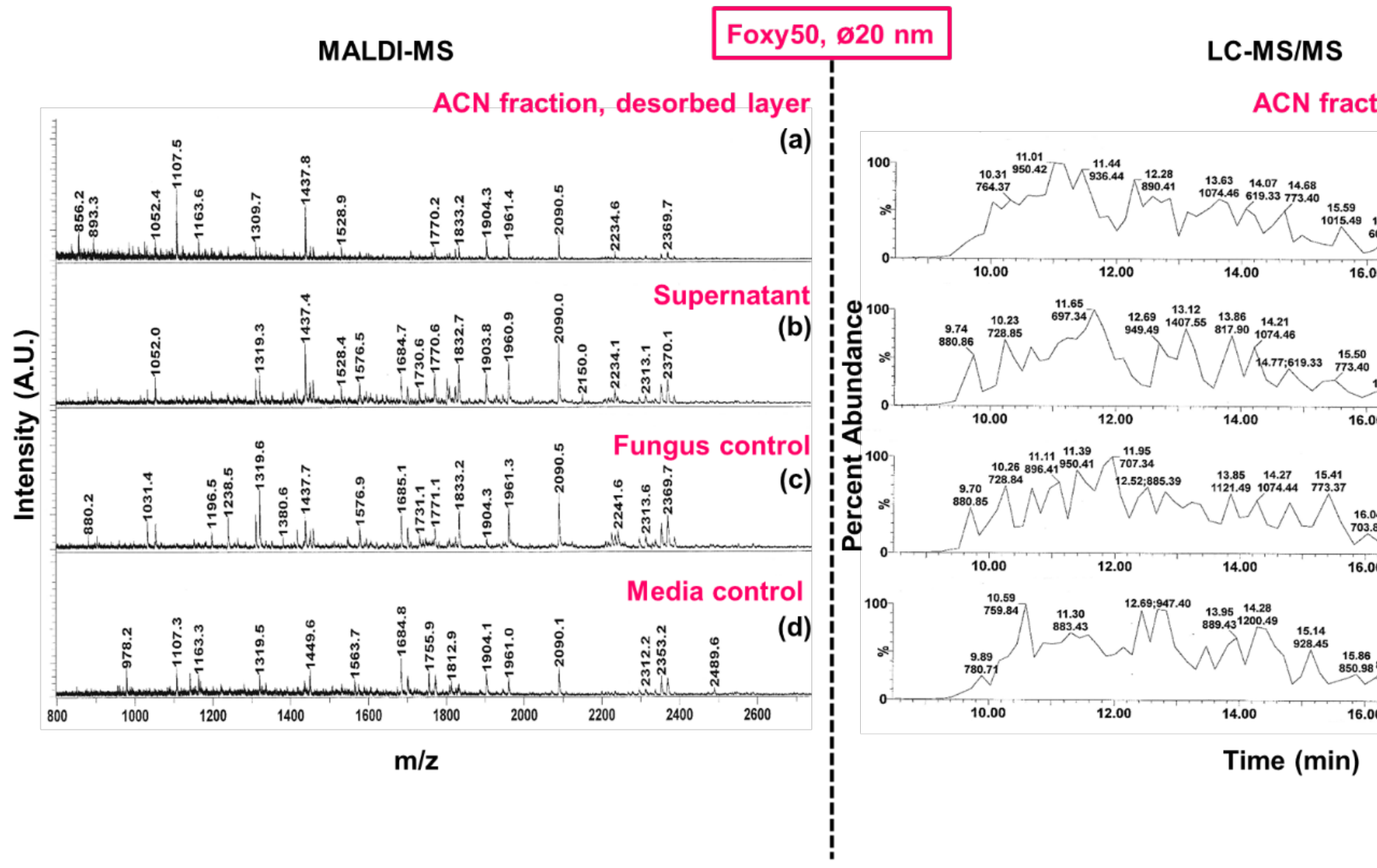

Figure S3. Mass spectrometry results from $\sim \varnothing 20 \mathrm{~nm}$ silver nanoparticles produced by Fusarium oxysporum at $50^{\circ} \mathrm{C}$ (Foxy50) compared to controls: fungus only with no silver nitrate exposure and media used to culture fungus. MALDI-MS spectra (a-d) are shown on the left and corresponding LC-MS/MS chromatograms (e-h) are shown on the right. (a and 
e) Results collected from an acetonitrile fraction containing the desorbed layer. (b and f) Results collected from the supernatant after centrifugation of silver nanoparticles. (c and g) Results collected from $F$. oxysporum culture filtrate in the absence of $1 \mathrm{mM}$ silver nitrate. $\left(\mathrm{d}\right.$ and $\mathrm{h}$ ) Results collected from $1 \%$ yeast-peptone-glucose media incubated at $50^{\circ} \mathrm{C}$. This media was used to initially culture $F$. oxysporum and used as a negative control during nanoparticle production.

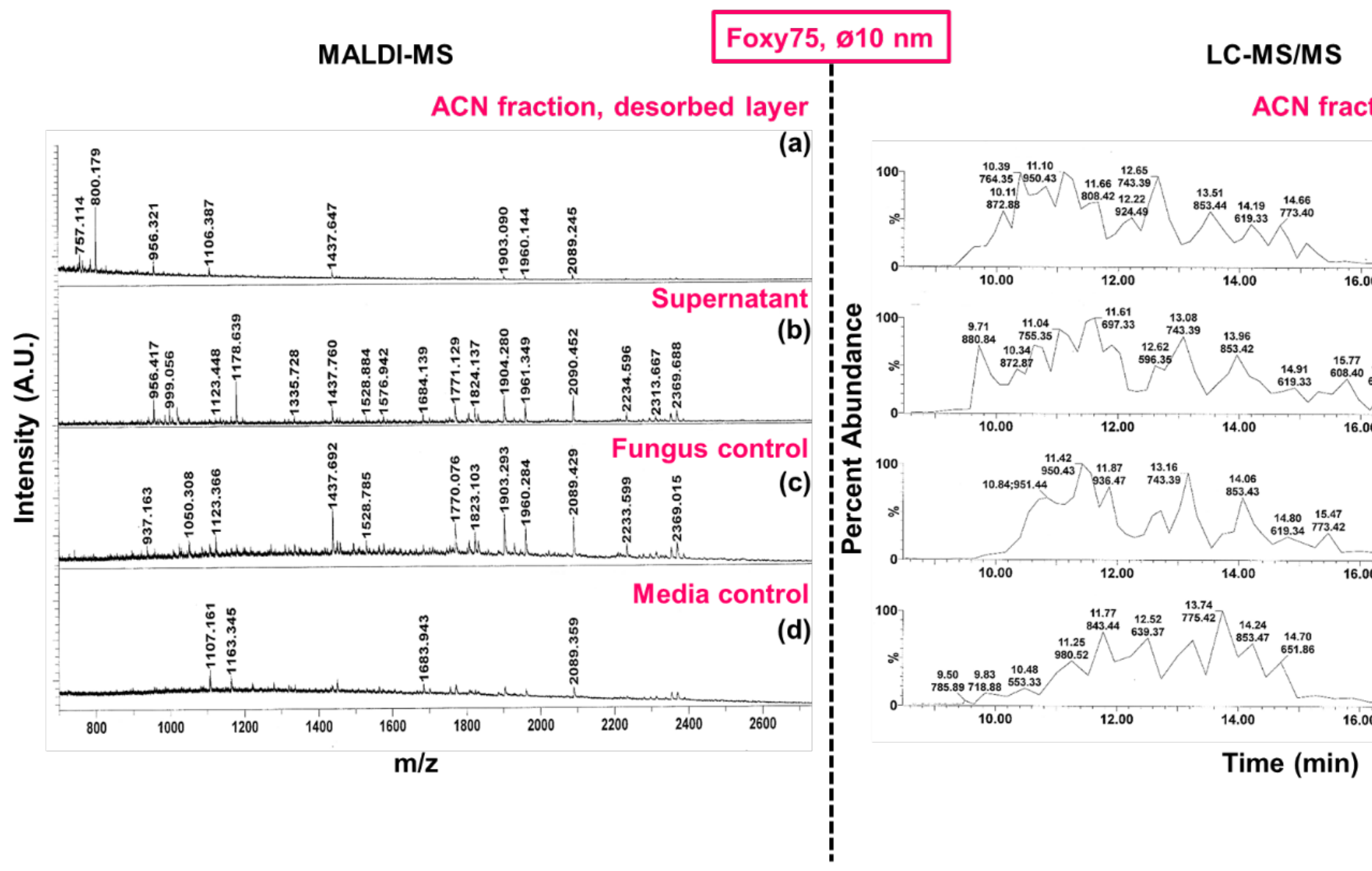

Figure S4. Mass spectrometry results from $\sim \varnothing 10 \mathrm{~nm}$ silver nanoparticles produced by Fusarium oxysporum at $75^{\circ} \mathrm{C}$ (Foxy75) compared to controls: fungus only with no silver nitrate exposure and media used to culture fungus. MALDI-MS spectra (a-d) are shown on the left and corresponding LC-MS/MS chromatograms (e-h) are shown on the right. (a and e) Results collected from an acetonitrile fraction containing the desorbed layer. ( $b$ and $f$ ) Results collected from the supernatant after centrifugation of silver nanoparticles. (c and g) Results collected from $F$. oxysporum culture filtrate in the absence of $1 \mathrm{mM}$ silver nitrate. $\left(\mathrm{d}\right.$ and $\mathrm{h}$ ) Results collected from $1 \%$ yeast-peptone-glucose media incubated at $50^{\circ} \mathrm{C}$. This media was used to initially culture F. oxysporum and used as a negative control during nanoparticle production. 

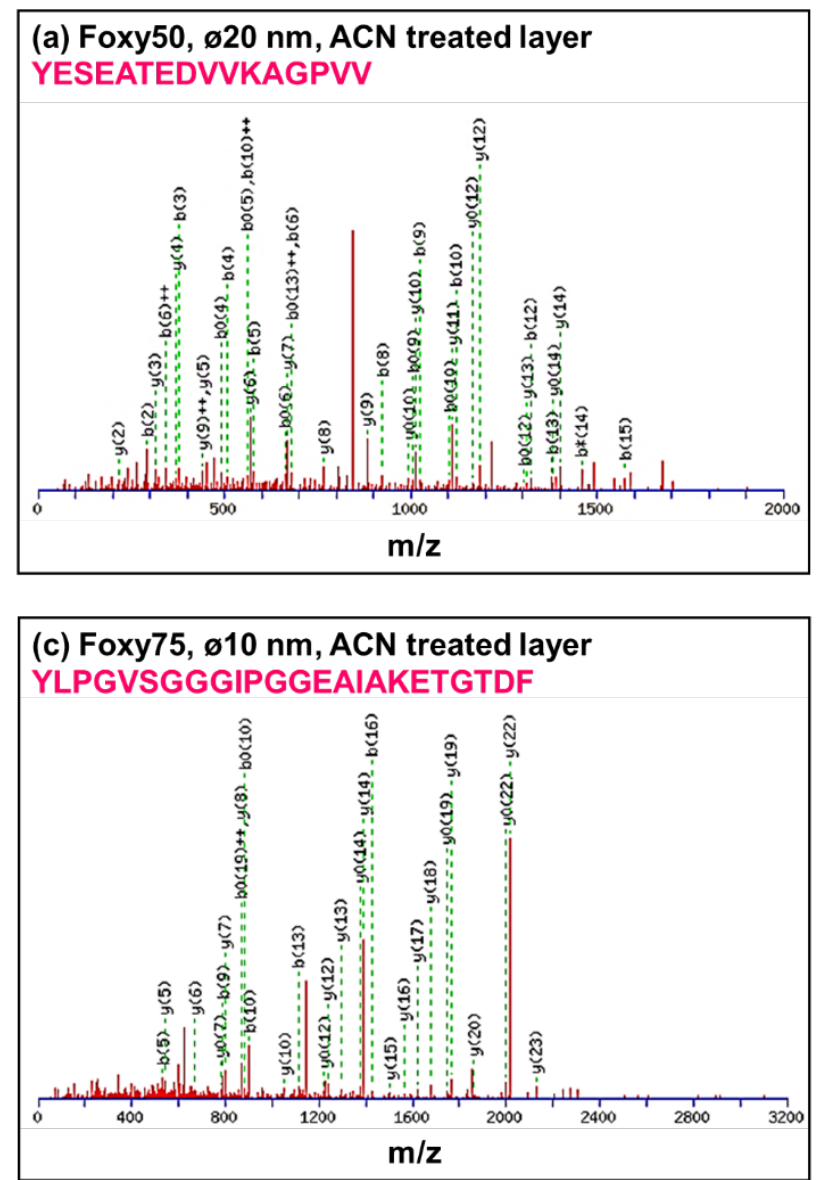

(e) Foxy50, Fungus control GLTGPIGPIGP

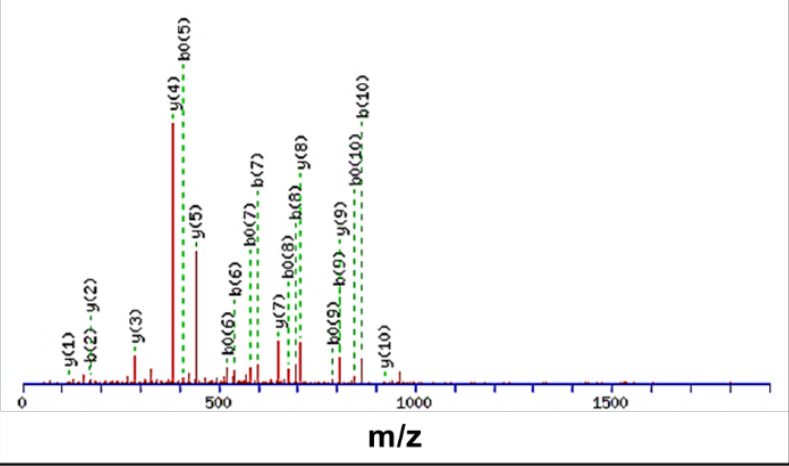

(b) Fox50, ø20 nm, supernatant DPLTREVDYDDATLT

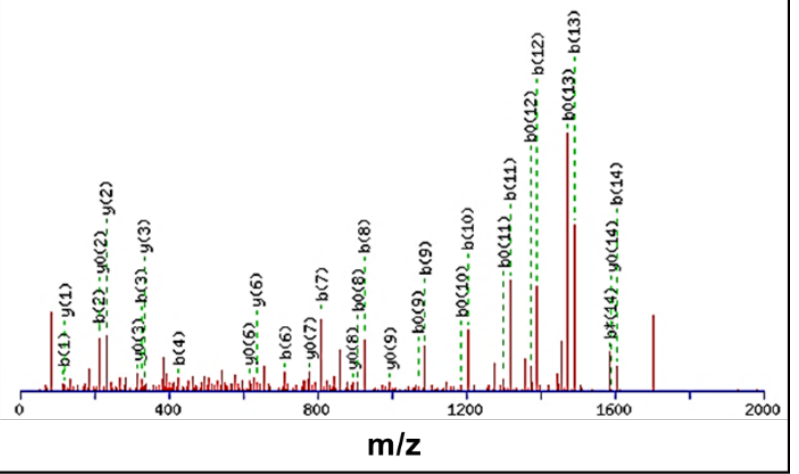

(d) Foxy75, ø10 nm, supernatant DGIEGVAMVAP

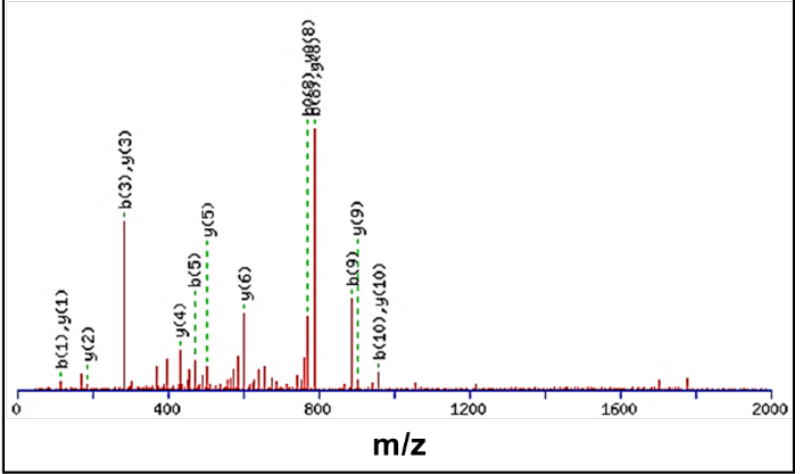

(f) Foxy75, Fungus control

TGPIGPIGP

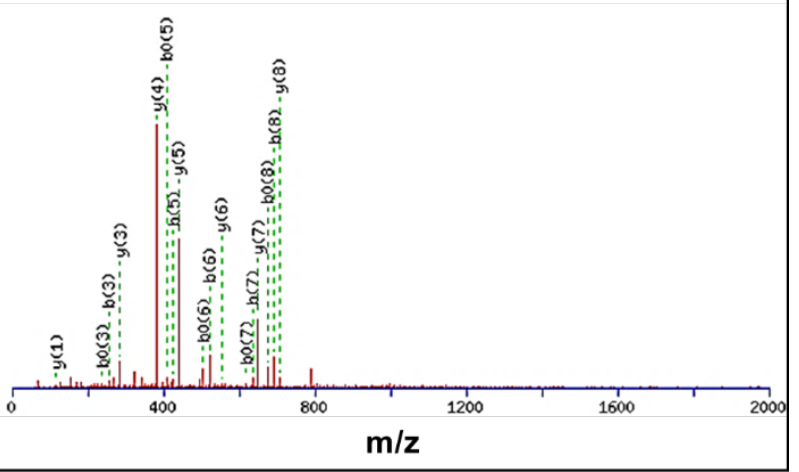

Figure S5. Tandem mass spectra of highest peptide scores for desorbed surface layer from $\sim \varnothing 20 \mathrm{~nm}$ and $\sim \varnothing 10 \mathrm{~nm}$ biogenic silver nanoparticles produced by Fusarium oxysporum (Foxy) at either $50^{\circ} \mathrm{C}$ or $75^{\circ} \mathrm{C}$. Plots of intensity as a function of mass to charge (m/z) ratio. (a) Surface layer desorbed from $\sim \varnothing 20 \mathrm{~nm}$ silver nanoparticles with acetonitrile (ACN). (b) supernatant fraction of $\sim \varnothing 20 \mathrm{~nm}$ silver nanoparticles post centrifugation. (c) Surface layer desorbed from $\sim ø 10 \mathrm{~nm}$ silver nanoparticles with ACN. (d) supernatant fraction of $\sim ø 10$ $\mathrm{nm}$ silver nanoparticles post centrifugation. (e-f) Control fungal filtrate at $50^{\circ} \mathrm{C}$ or $75^{\circ} \mathrm{C}$ without exposure to $1 \mathrm{mM} \mathrm{AgNO}_{3}$. 


\section{References}

1. Layne, E., Spectrophotometric and turbidimetric methods for measuring proteins. Methods Enzymol. 1957, 3, 447-454.

2. $\quad$ Stoscheck, C. M., Quantitation of Protein. In Methods Enzymol., Murray, P. D., Ed. Academic Press: San Diego: 1990; Vol. 182, pp 50-68. 
Illuminating the surface corona of biogenic silver nanoparti... (1.62 MiB) view on ChemRxiv • download file 